NOTICE: This is the accepted author manuscript of the publication

\title{
Altered mGluR5 binding potential and glutamine concentration in the 6-OHDA rat model of acute Parkinson's disease and levodopa-induced dyskinesia
}

Crabbé M, Van der Perren A, Weerasekera A, Himmelreich U, Baekelandt V, Van Laere K, Casteels C.

Published in Neurobiology of Aging

doi: 10.1016/j.neurobiolaging.2017.09.006

Available online 21 September 2017

Direct link to the final version of the article:

https://doi.org/10.1016/j.neurobiolaging.2017.09.006

(C) $<2017>$. This manuscript version is made available under the CC-BY-NC-ND 4.0 license http://creativecommons.org/licenses/by-nc-nd/4.0/ 


\section{Altered mGluR5 binding potential and glutamine concentration in the 6-OHDA rat model of acute Parkinson's disease and levodopa-induced dyskinesia}

\section{Authors:}

Melissa Crabbéa, ${ }^{\mathrm{a}, \mathrm{b}}$, Anke Van der Perren ${ }^{\mathrm{b}, \mathrm{c}}$, Akila Weerasekera ${ }^{\mathrm{b}, \mathrm{d}}$, Uwe Himmelreich $^{\mathrm{b}, \mathrm{d}}$, Veerle Baekelandt ${ }^{\mathrm{b}, \mathrm{c}}$, Koen Van Laere ${ }^{\mathrm{a}, \mathrm{b}}$, Cindy Casteels ${ }^{\mathrm{a}, \mathrm{b}, *}$

\section{Affiliations:}

${ }^{a}$ Division of Nuclear Medicine, Department of Imaging and Pathology, KU Leuven and University Hospital Leuven - B-3000 Leuven, Belgium

${ }^{\mathrm{b}}$ MoSAIC - Molecular Small Animal Imaging Centre, KU Leuven - B-3000 Leuven, Belgium

${ }^{\mathrm{c}}$ Laboratory for Neurobiology and Gene Therapy, Department of Neurosciences, KU Leuven - B-3000 Leuven, Belgium

${ }^{\mathrm{d}}$ Biomedical MRI Unit, Department of Imaging and Pathology, KU Leuven - B-3000 Leuven, Belgium

\section{* Corresponding author: Cindy Casteels, PhD; Nuclear Medicine \& Molecular Imaging, O\&N 1}

Herestraat 49 box 505, B-3000 Leuven, Belgium.

Tel.: +32 16330894

E-mail address: cindy.casteels@kuleuven.be 


\begin{abstract}
Several lines of evidence point to alterations in glutamatergic signaling in Parkinson's disease (PD) and levodopa-induced dyskinesia (LID), involving the metabotropic glutamate receptor type 5 (mGluR5). Using small-animal positron emission tomography (PET) with $\left[{ }^{18} \mathrm{~F}\right] \mathrm{FPEB}$, and proton magnetic resonance spectroscopy $\left({ }^{1} \mathrm{H}-\mathrm{MRS}\right)$, we investigated cerebral changes in the metabotropic glutamate receptor type 5 (mGluR5) and glutamate/glutamine availability in vivo in PD rats and following onset of LIDs. In parallel, behavioral tests were performed. Comparing PD to control rats, mGluR5 binding potential was decreased in a cluster comprising the bilateral caudate-putamen (CP), ipsilateral motor and somatosensory cortex, and the contralateral somatosensory and parietal association cortex, with the most pronounced reduction in the ipsilateral CP. mGluR5 binding potentials were not significantly altered upon L-DOPA treatment. However, following L-DOPA, an increase in relative mGluR5 uptake was present in the contralateral motor- and somatosensory cortex. Glutamate and glutamine concentrations did not differ between control and untreated PD rats, nor between hemispheres. Though glutamine levels were higher in the contralateral $\mathrm{CP}$ of saline- and levodopa-treated rats as compared to the ipsilateral side. Relative mGluR5 uptake in the $\mathrm{CP}$ of levodopa-treated rats was also found positively correlated with Abnormal Involuntary Movement scores (AIMS). Conclusively, mGluR5 availability and glutamine concentrations in the $\mathrm{CP}$ are involved in PD whereas mGluR5 availability in cortical regions may be involved in LID pathology.
\end{abstract}

Keywords: small-animal PET, Parkinson's disease, metabotropic glutamate receptor type 5, $\left[{ }^{18} \mathrm{~F}\right] \mathrm{FPEB}, 6$ OHDA rat model 


\section{INTRODUCTION}

Parkinson's disease (PD) is a neurodegenerative disorder, characterized by a loss of dopaminergic neurons in the substantia nigra pars compacta $\left(\mathrm{SN}_{\mathrm{pc}}\right)$ (Ma, et al., 1997,Niethammer, et al., 2013). Chronic L-3,4dihydroxyphenylalanine (levodopa) therapy has been considered the gold standard for its treatment. However, it does not arrest dopaminergic neuronal degeneration and is associated with detrimental side-effects, such as levodopa-induced dyskinesia (LID) (Fahn, 1974,Obeso, et al., 1989,Ziv, et al., 1997). LIDs are caused by a complex pattern of changes in the basal ganglia and cause characteristic chorea and dystonia (Duvoisin, 1974,Marsden and Parkes, 1976). Previous preclinical and clinical research have shown an upregulation of postsynaptic dopamine receptors upon PD progression, which lowers the threshold for the dyskinetic effect of levodopa, whereas altered neuroplasticity, caused by the therapy itself, leads to increasing severity of dyskinesia upon chronic treatment (Cenci and Lundblad, 2006,Jenner, 2000). Furthermore, several groups suggested an overactive glutamate transmission in the basal ganglia to be a key factor in the maladaptive plasticity of PD and LID (Bezard, et al., 2001,Chase and Oh, 2000).

At present, postponing the onset and reducing the severity of LID are still considerable issues in research. Among several non-dopaminergic strategies, metabotropic glutamate receptors (mGluRs) have recently been investigated as a novel target for the treatment of PD with and without LID. Of the eight receptor subtypes, the metabotropic glutamate receptor type 5 (mGluR5) has received increasing attention. mGluR5 is expressed postsynaptically in the striatopallidal synaptic cleft, where it is coupled with G-proteins to stimulate downstream modulators, including adenylyl cyclase, phospholipase $C-\beta$, and mitogen-activated protein kinase (Conn and Pin, 1997,Jong, et al., 2009). Besides the striatum, high densities of mGluR5 can also be found on neurons of the hippocampus, cerebral cortex and nucleus accumbens, as well as on immune cells such as astrocytes and microglia (Abe, et al., 1992,Byrnes, et al., 2009,Shigemoto, et al., 1993). mGluR5 has been reported to play a causal role in the development of PD-related motor and cognitive dysfunctions, and has neuroprotective properties in animal models (Battaglia, et al., 2004,Breysse, et al., 2003,Conn, et al., 2005,Morin, et al., 2014,Ossowska, et al., 2007). In early-stage PD rats, decreased mGluR5 expression was reported while, in later stages of the disease, an upregulation was noted in the CP, similarly to observations upon LID development (Jenkins, et al., 2015,Ouattara, et al., 2010,Ouattara, et al., 2011,Samadi, et al., 2008). Nonetheless the efficacy of several mGluR5 antagonists in phase II clinical trials remains inconclusive, demanding a more detailed understanding of the role of mGluR5 in PD and LID pathology (Tison, et al., 2016,Trenkwalder, et al., 2016). To 
our knowledge, no data is available correlating receptor and ligand (glutamate) status in vivo to disease severity, in a longitudinal design. In this manuscript, we therefore wish to investigate, for the first time, mGluR5 and glutamate/glutamine levels in vivo in the well-known 6-hydroxydopamine (6-OHDA) PD model, upon development of LID. To do this, we employed 3-(18)F-fluoro-5-(2-pyridinylethynyl) benzonitrile ([ $\left.\left.{ }^{18} \mathrm{~F}\right] \mathrm{FPEB}\right)$ microPET and ${ }^{1} \mathrm{H}-\mathrm{MRS}$, in relation to behavioral measures.

\section{MATERIALS \& METHODS}

\section{$2.1 \quad 6-O H D A$ animal model}

All animal experiments were performed according to the European Communities Council Directive of November $24^{\text {th }} 1986$ (86/609/EEC) and approved by the local Animal Ethics Committee of the KU Leuven. Experiments were conducted on 30 female Wistar rats (on average 8 weeks old; body weight range at the start of the experiment $193.6 \pm 11.7 \mathrm{~g}$ ). Animals had free access to pellet food and tap water, and were under a $12 \mathrm{~h}$ light/dark cycle. Stereotactic 6-hydroxydopamine (6-OHDA) injections into the substantia nigra pars compacta $\left(\mathrm{SN}_{\mathrm{pc}}\right)$ were executed in accordance to the protocol described by Van der Perren et al. (Van der Perren, et al., 2015). In short, animals were injected with $4 \mu 1$ containing either 6-OHDA $(n=20 ; 24 \mu \mathrm{g}$ dissolved in $4 \mu 1$ of $0.05 \%$ ascorbate saline) or ascorbate saline $(\mathrm{n}=10)$, using following coordinates for the $\mathrm{SN}_{\mathrm{pc}}$ : anteroposterior (AP) -5.3, lateral (LAT) -2.0, dorsoventral (DV) -7.2. All rats were allowed to recover from surgery for 21 days, before the start of the experiment. A detailed timeline of the experiment is shown in figure 1.6-OHDA- and saline-injected rats will be mentioned hereafter as PD and sham groups, respectively.

\subsection{Levodopa treatment}

To assess the effects of LID on mGluR5 and glutamate/glutamine levels, a subset of PD rats $(n=10)$ received levodopa (L-DOPA) therapy (6 mg/kg, i.p., L-DOPA methyl ester, Sigma Aldrich AB, Saint Louis, MO, USA) combined with a peripheral DOPA decarboxylase inhibitor, benserazide $(12 \mathrm{mg} / \mathrm{kg}$, i.p., benserazide $\mathrm{HCl}$, Sigma) twice daily for 2 weeks. L-DOPA and benserazide were dissolved in physiological saline $(2.0 \mathrm{~mL} / \mathrm{kg}$, i.p.) and administered in a single injection. Chronic treatment with this L-DOPA and benserazide dose has previously shown to cause a gradual development of LID-like movements in 6-OHDA-lesioned rats (Putterman, et al., 2007). Control treatment $(\mathrm{n}=10)$ consisted of injections with physiological $0.9 \%$ sterile saline $(2.0 \mathrm{~mL} / \mathrm{kg}$, i.p.). L-DOPA- and saline-treated rats will be noted hereafter as L-DOPA and saline groups, respectively.

\subsection{Small-animal PET imaging}


mGluR5 imaging was performed using the radioligand $\left[{ }^{18}\right.$ F]FPEB (3-(18)F-fluoro-5-(2pyridinylethynyl)benzonitrile). $\left[{ }^{18} \mathrm{~F}\right] \mathrm{FPEB}$ was synthetized on-site using the nitro-precursor obtained from $\mathrm{ABX}$ (Advanced Biochemical Compounds, Radeberg, Germany). To optimize synthesis, a chromafix anion exchange column conditioned with oxalate was used, with kryptofix in combination with the weaker base potassium oxalate for elution of the $\left[{ }^{18} \mathrm{~F}\right]$-fluoride from the cartridge. PET experiments were performed on a lutetium oxyorthosilicate detector-based small-animal tomograph (FOCUS-220; Siemens/Concorde Microsystems, Knoxville, TN, USA). This tomograph has a $1.35 \mathrm{~mm}$ full-width at half-maximum (FWHM) transaxial resolution. Data were collected in a $128 \times 128 \times 95$ matrix with a pixel width of $0.475 \mathrm{~mm}$ and $0.795 \mathrm{~mm}$ slice thickness.

Before and during PET imaging, rodents were anesthetized using $2.5 \%$ isoflurane in $100 \%$ oxygen $(1.5 \mathrm{l} / \mathrm{min}$ flow rate) and temperature was maintained at $\pm 37^{\circ} \mathrm{C}$. Tail veins were catheterized for injection of $17.45 \pm 2.58$ $\mathrm{MBq}(18 \mathrm{MBq} \sim 500 \mu \mathrm{Ci})\left[{ }^{18} \mathrm{~F}\right] \mathrm{FPEB}$ (specific activity range $85.8 \pm 42.5 \mathrm{GBq} / \mu \mathrm{mol}$ ). Dynamic 60 -min scans were initiated simultaneously with $\left[{ }^{18} \mathrm{~F}\right] \mathrm{FPEB}$ injection.

\subsection{PET image reconstruction and data processing}

List-mode data were reconstructed in 21 frames $(4 \times 15,4 \times 60,5 \times 180$ and $8 \times 300)$ using an iterative maximum a posterior probability (MAP) algorithm with ordered subsets (18 iterations, 9 subsets; fixed resolution: $1.5 \mathrm{~mm}$ ) and attenuation correction by means of a $\left[{ }^{57} \mathrm{Co}\right]$-attenuation scan.

PET images were normalized to a custom-made rat brain template in Paxinos stereotactic space (Casteels, et al., 2006). Ichise's original multi-linear reference tissue model (MRTM0) was utilized to generate parametric nondisplaceable binding potential $\left(\mathrm{BP}_{\mathrm{ND}}\right)$ images of $\left[{ }^{18} \mathrm{~F}\right] \mathrm{FPEB}$, using the cerebellum as reference tissue (de Laat, et al., 2015). When no absolute differences were found, we also studied relative $\left[{ }^{18} \mathrm{~F}\right] \mathrm{FPEB}$ uptake that was expressed as tracer uptake normalized to the whole-brain uptake at the $45-60$ min time interval, at which equilibrium was reached.

Voxel-wise analysis was performed using Statistical Parametric Mapping 8 (SPM8, Wellcome Department of Cognitive Neurology, London, United Kingdom). We used a 2-sample t-test for a cross-sectional comparison at the 3-week time point (i.e. sham vs. PD), and a flexible factorial design depending on time point (3 and 5 weeks) and treatment group (saline or L-DOPA). Spatially normalized images were masked to exclude extra-cerebral signal and smoothed with an isotropic Gaussian kernel of $1.2 \mathrm{~mm}$. SPM analysis was performed using a 0.8 relative threshold of mean image intensity, with and without global normalization. T-maps were interrogated at a $\mathrm{p}_{\text {height }} \leq 0.005$ (uncorrected) peak level and extend threshold of $\mathrm{k}_{\mathrm{E}}>200$ voxels $\left(1.6 \mathrm{~mm}^{3}\right)$. Only significant 
clusters with $\mathrm{p}_{\text {height }}<0.05$ (corrected for multiple comparisons) were retained. Exceptions on $\mathrm{p}_{\text {cluster }}$ were allowed for clusters which were plausible on a neurobiological basis and relevant in light of other findings in this study or previous research in 6-OHDA rats.

Cross-sectional and longitudinal VOI-based analysis was executed using a predefined VOI map including the caudate-putamen, hippocampus and cortex (PMOD, version 3.4, PMOD Technologies LTD, Zurich, Switzerland). In addition, we performed a voxel- and VOI-based correlation analysis between (1) mGluR5 binding, (2) glutamate/glutamine levels, and (3) behavioral outcomes.

\subsection{Magnetic resonance spectroscopy}

Single-voxel ${ }^{1} \mathrm{H}-\mathrm{MR}$ spectroscopy was performed in a small-animal $9.4 \mathrm{~T}$ magnet (Biospec 94/20, Bruker, Ettlingen, Germany) with a horizontal bore of $20 \mathrm{~cm}$ and equipped with an actively shielded gradient set (600

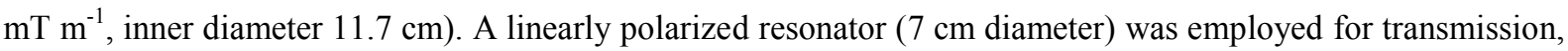
combined with a brain surface coil for receiving (both Bruker Biospin, Ettlingen, Germany). During scanning, rats were anaesthetized with 1-2\% isoflurane in $100 \%$ oxygen. Respiration and body temperature were continuously monitored and maintained at $60-80 \mathrm{~min}^{-1}$ and $\pm 37^{\circ} \mathrm{C}$, respectively. Spectra were acquired for both the ipsi- and contralateral CP at the mid-striatal level (voxel size $3 \times 2.5 \times 2.5 \mathrm{~mm}^{3}$ ), using a $\mathrm{T}_{2}$-weighted image. For acquisition, the PRESS pulse sequence was used with following parameters: repetition time $(\mathrm{TR})=1800 \mathrm{~ms}$, echo time $(\mathrm{TE})=20 \mathrm{~ms}$, and 320 averages. Using Bruker built-in routines, spectra were corrected for $\mathrm{B}_{0}$ instability as well as $\mathrm{B}_{0}$ drift. Shimming was performed using FASTMAP, resulting in a final water line width $<$ $15 \mathrm{~Hz}$. MR-spectra were processed using the jMRUI software package (www.jmrui.eu), including removal of the residual water peak, phase correction, and baseline correction. Signal quantification was performed with QUEST using a basis set of 18 metabolites. In this study, we focused on glutamate (Glu) and glutamine (Gln) concentrations but also on their sum $(=\mathrm{Glx})$.

\subsection{Behavioral testing}

All behavioral tests were executed during the light phase of the $12 \mathrm{~h} \mathrm{light/dark} \mathrm{cycle} \mathrm{for} \mathrm{PD} \mathrm{and} \mathrm{PD-LID,} \mathrm{i.e.} \mathrm{at}$ 3 and 5 weeks post-surgery, respectively. Tests were performed on 2 consecutive days, in the same order, and on similar time points throughout the day to reliably compare between groups. Cognitive and emotional capability was evaluated by the sucrose preference test (anhedonia), elevated plus maze (anxiety), and object recognition test (short- and long-term memory). Motor capability was tested with the cylinder test (only at week 3 to prove model validity), rotarod, and catwalk test. Abnormal involuntary movement score (AIMS) was conducted in LDOPA- and saline-treated rats to evaluate LID development. AIMS was performed at treatment day 1, 4, 7, 10, 
13 and 15 . The above-mentioned tests were chosen because of their ability to detect aberrant motor, cognitive, and emotional function, characteristic of PD animals.

\subsubsection{The limb-use asymmetry (cylinder) test}

This test was performed on both 6-OHDA and sham-injected animals at 3 weeks post-surgery. To assess forelimb usage, rats were allowed to explore a glass cylinder (20 cm diameter) for $5 \mathrm{~min}$, which was videotaped for analysis. The number of wall contacts by either left or right limb were counted per rat. Simultaneous contacts with both limbs were excluded and only supporting contacts were counted. Wall contacts were expressed as percentage wall contacts of the lesioned forelimb relative to the total number of contacts $(\% \mathrm{I})$.

\subsection{2 $\underline{\text { Rotarod }}$}

Prior to lesioning, rats were trained for 5 consecutive days on an accelerating rotarod ( 4 to 40 rounds per minute (RPM) in 5 minutes). Every day, each rat was trained 3 times, with a minimum of 20 minutes between each run. Rodents were considered trained if they could remain for $>90 \mathrm{sec}$ on the accelerating rod, after which baseline was taken. After surgery, rats were subjected to the same accelerating protocol and latency to fall off was recorded (expressed in seconds).

\section{$\underline{2.6 .3} \underline{\text { CatWalk }}$}

The Catwalk ${ }^{\mathrm{TM}}$ (Noldus Information Technology, Wageningen, The Netherlands) has been proven useful to detect gait disturbances in animal models of neurodegenerative diseases and allows for semi-automated quantification of a number of locomotor features, including among others stride length and interlimb coordination (Vandeputte, et al., 2010). The principle of this technique relies upon optical reflection of paw contact points using a fluorescent tube. Before 6-OHDA administration, rats were allowed to explore the Catwalk for 3 consecutive runs. Training was considered complete when rats crossed the Catwalk without stopping for at least 2 runs. The average out of 3 runs, with a minimum of 4 step sequences, was utilized for analysis.

\subsection{4 $\underline{\text { Sucrose preference test (SPT) }}$}

Rodents were evaluated for anhedonia in the SPT, adapted from Carvalho et al. (Carvalho, et al., 2013). In brief, animals were exposed to bottles, filled with tap water or $3 \%$ sucrose, for $48 \mathrm{~h}$. Sucrose preference was calculated as sucrose intake divided by total fluid intake (\% sucrose preference).

\section{$\underline{2.6 .5} \underline{\text { Elevated plus maze (EPM) }}$}

Animals were tested for anxious-like behavior in the EPM. The apparatus was positioned so that illumination did not reach the rat while positioned in the closed arm. In contrast, the open arm was uniformly lit. Animals were 
placed on the central junction between open and closed arm, and allowed to explore for 10 minutes while being videotaped. Time spent in open and closed arms, as well as compartment entries, were measured manually. Results were expressed as the proportion of time spent in each arm to the total time spent in the maze (\% time spent in open or closed arm), and the number of entries in the open/closed arm divided by the total number of entries ( $\%$ entries into open or closed arm).

\subsubsection{Novel Object Recognition Test (NORT)}

The test was performed in an open arena in which 2 plastic objects $(12 \mathrm{~cm}$ length, $8 \mathrm{~cm}$ width, $6 \mathrm{~cm}$ height $)$ were placed. The NORT consisted of 3 sessions: an acquisition trial $(5 \mathrm{~min})$ and 2 test trials $(3 \mathrm{~min}$ duration), respectively 2 and 24 hours after the acquisition trial. During the acquisition trial, each rat was placed in the middle of an open arena, equidistant from 2 identical objects (objects A), and were allowed to explore. For the test trial, one familiar object (A) was replaced with a novel one (object B; $12 \mathrm{~cm}$ length, $6.5 \mathrm{~cm}$ width, $8.5 \mathrm{~cm}$ height) and again allowed to explore. The next day, rats were again allowed to investigate one familiar object (A) and a different object (C; $11 \mathrm{~cm}$ length, $10 \mathrm{~cm}$ width, 6.5 height). The time spent exploring, i.e. sniffing each object, was recorded manually. The arena and objects were thoroughly cleaned between sessions to impede odor clues. The recognition index (RI) was calculated by $\left(\mathrm{T}_{\mathrm{B} / \mathrm{C}} /\left(\mathrm{T}_{\mathrm{A}}+\mathrm{T}_{\mathrm{B} / \mathrm{C}}\right)\right) \mathrm{x} 100$, with $\mathrm{T}_{\mathrm{A}}$ as the time spent exploring the familiar object $\mathrm{A}$ and $\mathrm{T}_{\mathrm{B} / \mathrm{C}}$ as time spent exploring novel object $\mathrm{B}$ (short-term memory) or $\mathrm{C}$ (long-term memory).

\section{$\underline{\text { 2.6.7 Abnormal Involuntary Movement Scoring (AIMS) }}$}

Dyskinesia were recorded at day 1, 4, 7, 10, 13, and 15 upon treatment of L-DOPA. Rat behavior was recorded from 0 to $140 \mathrm{~min}$ after L-DOPA or vehicle injection and scored every $20^{\text {th }}$ minute. AIM scoring was performed as described previously (Lundblad, et al., 2002), with the exception that subtypes were scored on a severity scale from 0 to 3 (1, present $<50 \%$ of observation time; 2 , present $>50 \%$ of the observation time; 3 , present continuously; note that no sensory stimuli were provided to discriminate between score 3 or higher). The theoretical maximum score per session was calculated by multiplying the maximum score per time point (12) with the number of time points per session (7).

\subsection{Western blotting}

An additional cohort of saline-injected $(n=4)$ and 6 -OHDA injected $(n=4)$ rats was included for western blot analysis. The caudate-putamen of each animal was dissected at 3 weeks post-injection and resuspended in 400 $\mu \mathrm{L}$ of buffer containing $10.0 \mathrm{mM}$ TRIS, $1 \mathrm{mM}$ EDTA, $0.25 \mathrm{M}$ sucrose ( $\mathrm{pH}$ 7.4), and protease inhibitors 
homogenized and sonicated $(3 \times 15 \mathrm{sec})$, followed by incubation at $2000 \mathrm{rpm}$ for $5 \mathrm{~min}$. Aliquots from each fraction were used for determination of protein concentration using the BCA protein assay kit (Biorad, Richmond, CA, USA), according to the manufacturers' directions. Equal amounts of protein per sample $(30 \mu \mathrm{g})$ were diluted in loading buffer with $10 \%$ ß-mercaptoethanol. The samples were then heated for $5 \mathrm{~min}$ at $95{ }^{\circ} \mathrm{C}$ and centrifuged at $2000 \mathrm{rpm}$ for $2 \mathrm{~min}$. Samples were electrophoresed on a 3-8 \% Tris-Acetate gel (Criterion ${ }^{\mathrm{TM}}$ XT, Biorad) with XT Tricine running buffer (Biorad) and the PageRuler ${ }^{\mathrm{TM}}$ Plus Prestained Protein Ladder (Thermo Scientific, Portsmouth, NH, USA). After electrophoresis, gels were blotted onto a PVDF membrane for $10 \mathrm{~min}$ at $25 \mathrm{~V}$ using the Trans-Blot Turbo ${ }^{\mathrm{TM}}$ Transfer System (Biorad), following the manufacturers' protocol. Immunoblots were blocked in $5 \%$ dry milk in PBS with $0,1 \%$ Triton X-100 and probed with polyclonal rabbit anti-mouse mGluR5 (1:1000, AB5675, Millipore, Billerica, MA, USA) overnight at $4{ }^{\circ} \mathrm{C}$. Anti- $\alpha$-tubulin (1:1000, Sigma) was used as internal loading control. Subsequently immunoblots were incubated with goat antirabbit/mouse HRP-conjugated secondary antibodies (1:10.000, DakoCytomation, Belgium) for $90 \mathrm{~min}$ at room temperature. Bands corresponding to proteins were visualized using Pierce ECL Western Blotting Substrate (Thermo Scientific) in a LAS-3000 mini system (Fujifilm). Densitometry analysis was performed using LAS3000 Fujifilm software (Aida Image Analyzer V4.19).

\subsection{Histology and stereological quantification}

Rats were sacrificed using a sodium pentobarbital overdose $\left(60 \mathrm{mg} / \mathrm{kg}\right.$, i.p., Nembutal ${ }^{\text {, }}$, Ceva Santé Animale, Brussels, Belgium) after which intracardial perfusion was performed with $10 \%$ glucose in phosphate-buffered saline (PBS), followed by $4 \%$ paraformaldehyde in PBS. After $24 \mathrm{~h}$ post-fixation, samples were kept at $4{ }^{\circ} \mathrm{C}$ until further processing. Sectioning and subsequent immunohistochemistry were performed in accordance with Van der Perren et al. (Van der Perren, et al., 2015). Shortly, we used antibodies targeting the tyrosine hydroxylase (TH) enzyme (rabbit polyclonal 1:1000, Chemicon 152), and biotinylated anti-rabbit IgG as a secondary antibody (1:300, DakoCytomation), followed by incubation with streptavidin-horseradish peroxidase complex (1:1000, DakoCytomation), and employing Vector SG (SK-4700, Vector Laboraties, CA, USA) as a chromogen. For stereological quantification, the number of TH-positive cells were determined by the optical fractionator method in an automated system (StereoInvestigator; MicroBright-Field, Magdeburg, Germany) (Baekelandt, et al., 2002,Van der Perren, et al., 2015).

\subsection{General statistics}

Reported values are described as the mean \pm standard deviation. Cross-sectional group comparisons of VOI and behavioral data were performed using non-parametric Mann-Whitney U tests (PRISM, GraphPad Software, Inc., 
CA, USA) whereas within-animal comparisons were executed through the Wilcoxon signed-rank test. L-DOPA time effects were tested for statistical significance using a two-way analysis of variance (ANOVA). Bonferroni post-hoc tests were utilized to correct for multiple comparisons. PET, MRS and behavioral results were correlated using Spearman rank correlation in PRISM. P-values $<0.05$ were accepted as statistically significant.

\section{RESULTS}

\subsection{Validation of the 6-OHDA rat PD model}

We injected Wistar rats in the $\mathrm{SN}_{\mathrm{pc}}$ with 6-OHDA to induce dopaminergic neurodegeneration. Three weeks postinjection, these rats presented significant limb-use asymmetry when subjected to the cylinder test, as compared to sham-injected rats at week 3 (\% left forepaw use: $29.3 \pm 9.4$ vs. $49.5 \pm 4.6 ; p<0.001$; Fig. 2A). This finding was validated by quantitative histological analysis which showed an average unilateral degeneration of $95.14 \%$ (range $89.6 \%$ to $99.0 \%$ ) of TH-positive neurons in the $\mathrm{SN}_{\mathrm{pc}}$ of all PD rats 5 week post-injection (Fig. 2B).

\subsection{Small-animal $\left[{ }^{18}\right.$ F]FPEB PET imaging}

Mean cross-sectional images of $\left[{ }^{18} \mathrm{~F}\right]$ FPEB binding in the rat brain of 6-OHDA-lesioned, L-DOPA-treated, and control rats are shown in Fig. 3. As previously described (de Laat, et al., 2015,Romano, et al., 1995), $\left[{ }^{18}\right.$ F]FPEB showed a regional distribution corresponding to mGluR5 densities, with high uptake in the caudate-putamen, hippocampus, and cortex.

Voxel-based comparison between sham and $\mathrm{PD}$ rats revealed reduced mGluR5 $\mathrm{BP}_{\mathrm{ND}}$ values in a cluster comprising the ipsi- and contralateral $\mathrm{CP}$, ipsilateral motor- and somatosensory cortex, and the contralateral somatosensory and parietal association cortex $\left(\mathrm{p}_{\text {height }}<0.005\right.$; mean decrease at Paxinos coordinate peak maximum: $-12.0 \% \pm 3.5 \% ; \mathrm{p}=1.2 \times 10^{-6}$; Fig. 3 and $4 \mathrm{~A}$ ). More specifically, decreased mGluR5 BP $\mathrm{ND}_{\mathrm{Nas}}$ focused in the ipsilateral CP of PD rats at $\mathrm{p}_{\text {height }}<0.001$. Reduced ipsilateral mGluR5 expression was confirmed by western blotting where mGluR5 expression was (non-significantly) decreased by $29 \%$ in the ipsilateral CP of 6-OHDA-lesioned rats $(\mathrm{p}=0.1$; Mann-Whitney U test; Supplementary Figure 1). At the 5-week time point, mGluR5 $\mathrm{BP}_{\mathrm{ND}}$ did not differ significantly between saline- and L-DOPA-treated rats.

When looking at relative mGluR5 changes by scaling to the global mean tracer uptake, we confirmed diminished mGluR5 availability in the ipsilateral caudate-putamen and somatosensory cortex of PD rats in comparison to sham animals (mean decrease at Paxinos coordinate peak maximum: $-14.9 \% \pm 1.1 \% ; \mathrm{p}=4.6 \times 10^{-6}$ ). Additionally, elevated mGluR5 uptake was noted in the contralateral motor- and somatosensory cortex of L- 
DOPA-treated rats, in comparison to saline-treated animals at week 5 post-injection (mean increase at Paxinos coordinate peak maximum: $+7.6 \% \pm 6.2 \% ; \mathrm{p}=2.3 \times 10^{-4}$; Fig. 5). Detailed cluster peak locations and $\mathrm{p}$-values of the voxel-based categorical analysis using SPM are shown in table 1. VOI-based findings of the CP were in agreement with the voxel-based analysis though the smaller cortical regions could not be picked up by VOIanalysis. Two PD rats and 1 sham rat could not be scanned at week 3 and were therefore not included in the PET data analysis.

\section{$3.3 \quad{ }^{1} \mathrm{H}-\mathrm{MRS}$ of the caudate-putamen}

Comparison between sham- and 6-OHDA-lesioned PD animals did not show significantly altered glutamate or glutamine metabolite levels in the ipsi- or contralateral caudate-putamen, 3 weeks post-injection (Fig. 6B). In both saline- and L-DOPA treatment groups, glutamine concentrations were found significantly higher in the contralateral caudate-putamen at 5 weeks post-injection, as compared to the lesioned side (saline: $3.65 \pm 0.48$ $\mathrm{mmol} / \mathrm{kg}$ vs. $3.05 \pm 0.35 \mathrm{mmol} / \mathrm{kg} \sim+16 \%$; L-DOPA $3.51 \pm 0.40$ vs. $2.98 \mathrm{mmol} / \mathrm{kg} \pm 0.44 \mathrm{mmol} / \mathrm{kg} \sim+15 \%$; $=0.003$ and $\mathrm{p}=0.002$, respectively; Fig. $6 \mathrm{C}$ ) which suggests a time-dependent effect. This trend was also visible in Glx concentrations but remained non-significant.

\subsection{Behavioral outcome}

To test motor coordination and balance in rodents, we used the accelerating rotarod and catwalk test, which are classical tests used in rodents bearing dopaminergic lesions. Latency to fall of the rod was significantly lower in 6-OHDA-lesioned rats compared to their baseline performance $(152.5 \pm 58.1$ sec vs. $99.0 \pm 34.2$ sec, respectively; $\mathrm{p}=0.001)$, but not when comparing to sham control animals $(99.6 \pm 42.9 \mathrm{sec}$, NS). L-DOPA treatment also did not induce any significant differences in rotarod performance.

In the catwalk test, lesioning of the $\mathrm{SN}_{\mathrm{pc}}$ led to a significantly lower swing speed of the contralateral front and hind paws compared to the ipsilateral side (front paws: $52.3 \pm 6.8 \mathrm{~mm} / \mathrm{s}$ vs. $40.2 \pm 8.3 \mathrm{~mm} / \mathrm{s}, \mathrm{p}<0.001$; hind paws: $62.1 \pm 10.3 \mathrm{~mm} / \mathrm{s}$ vs. $46.5 \pm 10.4 \mathrm{~mm} / \mathrm{s}, \mathrm{p}=0.002$; Fig. 7A). L-DOPA treatment led to elevated duty cycle of the hind paws $(40.39 \pm 11.09 \%$ vs. $54.85 \pm 3.72 \%$; $=0.004$; Fig. 7 B $)$ which indicates stance duration as a percentage of the duration of the step cycle. Elevated duty cycle following L-DOPA therapy thus signifies that the paws of L-DOPA animals were longer in contact with the glass plate as compared to saline-treated animals. In addition, we found the percentage of diagonal support to be higher in L-DOPA versus saline animals (55.91 \pm $10.27 \%$ vs. $27.49 \pm 12.10 \% ; \mathrm{p}<0.001 ;$ Fig. $7 \mathrm{C})$.

Anxious-like behavior was assessed using the elevated plus maze test. PD-lesioned animals spent significantly less time in the open arms compared to closed arms (\% time in open arm: $9.0 \pm 12.2 \%$ vs. closed arm $57.6 \pm$ 
$34.4 \% ; \mathrm{p}<0.001 ;$ Fig. 7D) while sham rats did not depict a significant preference between open or closed arms $(21.1 \pm 34.4 \%$ vs. $50.9 \pm 37 . \%$; NS). This effect could not be attributed to motor activity since the number of arm entries was not significantly different between PD and sham groups. This preference for the closed arm persisted in L-DOPA- as well as saline-treated rats but was not significantly different between therapies (\% time in open arm: $0.8 \pm 1.6 \%$ vs. $3.2 \pm 9.6 \%$, respectively, NS).

Short-term memory was tested using the novel object recognition test. Short-term memory was significantly altered in 6-OHDA-lesioned rats, as indicated by an increased recognition index, compared to sham-operated rats (RI: $60.5 \pm 20.2 \%$ vs. $37.6 \pm 17.8 \%$, respectively; $\mathrm{p}=0.005$; Fig. $7 \mathrm{E}$ ) while no alterations in long-term memory were present (PD: $76.8 \pm 11.4 \%$ vs. sham: $87.0 \pm 12.8 \%$ ). Two weeks of L-DOPA treatment did not lead to significantly different short- or long-term memory.

The sucrose preference test was used to screen for anhedonia. Both drug-naïve PD and L-DOPA-treated rats showed a decreased sucrose preference, however not significant (\% sucrose preference: sham: $92.2 \pm 3.2$ vs. PD: $88.2 \pm 11.2 ; \mathrm{NS}$, and L-DOPA: $93.6 \pm 7.0$ vs. saline: $98.6 \pm 0.9 ; \mathrm{NS})$.

All rats developed dyskinesia following 2 weeks of L-DOPA treatment as indicated by increasing total AIM scores of $0.5 \pm 0.6$ at day 1 to $27.9 \pm 18.5$ at day 15 . AIM scores upon L-DOPA therapy were significantly greater than scores from saline-treated rats at 20 to 100 min post-administration (average total AIMS: L-DOPA: $27.9 \pm 18.5$ vs. SALINE $5 \pm 3 ; p<0.001)$, though 3 rats only reached significant AIM scores at day 15 . AIM scores of L-DOPA- and saline-treated rats are shown in figure 7F over a 140 min time period post-injection.

\subsection{Correlation analysis of $\left[{ }^{18}\right.$ F]FPEB binding and glutamate/glutamine concentrations with}

\section{behavioral testing}

VOI-based correlation revealed a positive correlation within relative mGluR5 uptake in the ipsilateral caudateputamen and AIM scores of L-DOPA-treated rats $(r=0.79, p=0.006$; Fig. 7C). No other correlations were observed within VOI- or voxel-based mGluR5 $\mathrm{BP}_{\mathrm{ND}}$ values, glutamate/glutamine levels and behavioral tests of 6-OHDA rats, with and without LID.

\section{DISCUSSION}

Aberrant glutamatergic signaling has long been implicated in Parkinson's disease (PD) and L-DOPA-induced dyskinesia (LID) (Bezard, et al., 2001). Hereby, the mGlu5 receptor has been described as a key factor with neuroprotective properties which also offers symptomatic relief of both PD and LID motor manifestations in rodent and primate models (Battaglia, et al., 2004,Breysse, et al., 2003,Conn, et al., 2005,Ossowska, et al., 
2007). On the other hand, several mGluR5 antagonists have shown little efficacy in clinical trials, which pleads for a more thorough understanding of mGluR5 status in PD and LID in order to explain the discrepancy between human and animal data (Tison, et al., 2016,Trenkwalder, et al., 2016).

In this report, we characterized, for the first time, the mGlu5 receptor and its ligand in vivo in the brain of drugnaïve PD rats and upon development of LID. We found $\left[{ }^{18} \mathrm{~F}\right] \mathrm{FPEB}$ binding potential significantly decreased in the bilateral caudate-putamen, which was most pertinent on the ipsilateral side, and spread towards the bilateral somatosensory cortex, the ipsilateral motor cortex, and the contralateral parietal association cortex. Treatment effects, on the other hand, were more subtle. L-DOPA treatment led to increased relative $\left[{ }^{18}\right.$ F]FPEB uptake in the contralateral motor- and somatosensory cortex.

Our report of decreased $\left[{ }^{18} \mathrm{~F}\right] \mathrm{FPEB}$ binding in the ipsilateral caudate-putamen of PD rats is in line with findings published by Jenkins et al., who reported $12 \%$ lower $\left[{ }^{18} \mathrm{~F}\right] \mathrm{FPEB}$ binding in the caudate-putamen ipsilateral to the lesioned $\mathrm{SN}_{\mathrm{pc}}$ of 6-OHDA-lesioned rats (Jenkins, et al., 2015). These authors evaluated mGluR5 availability at a similar time point (i.e. 4 weeks post-injection), and also after induction of a full unilateral lesion in the $\mathrm{SN}_{\mathrm{pc}}$ of the rat, which allows for a valid comparison. Jenkins et al. also described decreased mGluR5 binding as an early response to 6-OHDA administration since mGluR5 binding recovered over a 14-month period (+46\%), albeit that this recovery was marked by high variability between rats. In the same study, administration of a negative allosteric mGluR5 modulator led to bilaterally altered cerebral blood volume in the somatosensory cortex, which was most pronounced on the ipsilateral side. Since cerebral blood volume is considered a metabolic marker, this finding suggests a connection between mGluR5 and functional activity of the somatosensory cortex, which was also indicated in our research by altered mGluR5 in this region. To further confirm altered $\left[{ }^{18} \mathrm{~F}\right] \mathrm{FPEB}$ binding in our study, we also showed reduced mGluR5 expression in the ipsilateral caudate-putamen of PD rats, by western

blot analysis at the 3-week time point. However, significance was not reached which could be attributed to the fact that the entire caudate-putamen was isolated for western blotting while $\left[{ }^{18} \mathrm{~F}\right] \mathrm{FPEB}$ alterations where limited

\section{to the dorsal caudate-putamen.}

In addition, previous research has shown that monoamine levels (i.e. dopamine and serotonin), as well as basal glutamate output in the caudate-putamen were affected bilaterally following unilateral 6-OHDA injection in the $\mathrm{SN}_{\mathrm{pc}}$, similar to mGluR5 levels in this study (Branchi, et al., 2010,Pierucci, et al., 2009). Histological data confirms the presence of interhemispheric projections from the SN to the caudate-putamen (Morgan and Huston, 
1990), while electrophysiological data indicates that signaling of dopaminergic neurons in the substantia nigra are also affected by the contralateral brain (Castellano and Rodriguez Diaz, 1991,Rodriguez, et al., 1990).

In addition, Zhu and colleagues observed a small (but not statistically different) decline in $\left[{ }^{18} \mathrm{~F}\right] \mathrm{FPEB}$ binding at 7 weeks post-op, employing partial lesioning of the median forebrain bundle (MFB) as 6-OHDA PD model (Zhu, et al., 2013). At a similar time point, Zhu and coworkers observed a modest increase of $\left[{ }^{11} \mathrm{C}\right] \mathrm{MPEP}$ binding in the lesioned caudate-putamen of 6-OHDA rats, targeted in the MFB (Zhu, et al., 2007). Arguably, both of the latest mentioned studies employed PD models with only partial lesioning of the $\mathrm{SN}_{\mathrm{pc}}$, possibly reflecting an earlier disease stage in PD patients, while in our study, neurons of the $\mathrm{SN}_{\mathrm{pc}}$ showed excessive degeneration ( $<10 \%$ tyrosine hydroxylase-positive neurons remaining). Upon the development of LID, we found a modest upregulation of relative mGluR5 uptake in the contralateral motor- and somatosensory cortex but not in the caudate-putamen - of L-DOPA-treated rats as compared to saline-treated rats, using a voxel-based approach. This finding suggests a more important role for this region in LID pathology.

To our knowledge, no other rat studies exist which longitudinally evaluate mGluR5 levels in vivo during LID development. Following 1 month of L-DOPA treatment, one cross-sectional study in MPTP primates noted an $18 \%$ increased $\left[{ }^{11} \mathrm{C}\right] \mathrm{MPEP}$ binding in the motor regions of the caudate-putamen while others reported an increased mGluR5 binding in the posterior caudate nucleus and putamen of dyskinetic compared to nondyskinetic animals (Morin, et al., 2014,Ouattara, et al., 2010,Samadi, et al., 2008,Sanchez-Pernaute, et al., 2008). Remarkably, only Sanchez-Pernaute and colleagues looked at mGluR5 binding in additional brain structures besides the caudate-putamen and globus pallidus. In their study, (non-significantly) increased $\left[{ }^{11} \mathrm{C}\right] \mathrm{MPEP}$ binding was found in the bilateral primary, premotor and supplementary motor cortex, with high variability between L-DOPA-treated MPTP primates (Sanchez-Pernaute, et al., 2008). This is largely in agreement with our findings though Sanchez-Pernaute investigated primates with bilateral PD.

Despite we showed altered $\left[{ }^{18}\right.$ F]FPEB binding potential, pointing to a role for mGluR5 in PD and LID, other contributing mechanisms such as alterations in receptor affinity, conformational state, and neuroinflammation cannot be fully excluded. Recently, Haas et al. showed increased microglial and astrocyte infiltration into the $\mathrm{CP}$ of 6-OHDA-lesioned mice, targeted intranigrally, albeit limited at 14 days post-surgery (Haas, et al., 2016).

Altogether, our PET data suggest a downregulation of mGluR5 soon after degeneration of dopaminergic neurons, which could be part of a compensatory mechanism to counteract the loss of dopaminergic signaling into the caudate-putamen. The mGlu5 receptor has previously been shown to counteract the dopaminergic receptor type 2 (D2), possibly as a means to maintain homeostasis in the indirect pathway (Fuxe, et al., 2003). Putaminal 
D2 receptors have been shown to be upregulated in drug-naïve patients with early stage PD, further supporting this hypothesis (Kaasinen, et al., 2000,Scherfler, et al., 2006). Possibly, as the disease progresses, and upon chronic L-DOPA treatment, compensation mechanisms fail and an mGluR5 upregulation takes place, as demonstrated in the present work, primarily affecting the cortical regions. In line with this, several studies have shown that mGluR5 antagonism has beneficial effects on LID symptoms, especially when given along with LDOPA treatment (Bezard, et al., 2014,Morin, et al., 2014,Rylander, et al., 2010).

In the present study, 6-OHDA lesioning of the $\mathrm{SN}_{\mathrm{pc}}$ in rats did not lead to altered glutamate levels in the caudateputamen, as evaluated by ${ }^{1} \mathrm{H}-\mathrm{MRS}$, despite marked changes in mGluR5 availability. However, glutamine levels were significantly higher in the contralateral caudate-putamen of both saline- and L-DOPA-treated rats, which may indicate a time-dependent rather than a treatment-dependent effect. Our results are in line with several ${ }^{1} \mathrm{H}-$ MRS studies conducted in PD patients that did not observe glutamate changes in the caudate nucleus or putamen (Clarke, et al., 1997,Kickler, et al., 2007,Taylor-Robinson, et al., 1999). In 6-OHDA rats, Coune et al. reported a modest $6 \%$ glutamate decrease in the ipsilateral caudate-putamen of MFB-lesioned rats while no differences were reported in the $\alpha$-synuclein viral vector (rAAV2/6) overexpression model (Coune, et al., 2013). A possible disadvantage of MRS is that this technique cannot distinguish between extra- and intracellular metabolite concentrations. Nonetheless MRS does allow for non-invasive longitudinal measurements, in contradiction to other techniques, such as microdialysis, which makes it an outstanding technique for long-term follow-up. In accordance to our results, Robelet and colleagues did not detect differences in glutamate levels using in vivo microdialysis although L-DOPA treatment did cause a substantial rise in glutamate levels (Robelet, et al., 2004). In contrast, amperometric data indicated decreased basal extracellular glutamate (- $30 \%)$ in 6-OHDA-lesioned rats while upon L-DOPA treatment, basal glutamate levels were not different from controls (Nevalainen, et al., 2013). Notably, these measures were performed at different time points, toxin concentrations, and injection sites. Altogether, altered glutamine concentrations in the caudate-putamen of both saline- and L-DOPA-treated rats could possibly be a result of progressively decreased production or increased metabolism in that region. Aberrant activity of the glutamine synthetase enzyme has been reported in PD patients (Zipp, et al., 1998). Similarly, the rate of glutamine deamination, an energy producing reaction, could be enhanced as a compensation mechanism for decreased glucose levels in the brain, which was also noted in this study (data not shown) (Hu, et al., 2000,Kanamatsu, et al., 2007). 
Motor performance of PD rats was significantly impaired after injection of 6-OHDA intranigrally. Previously it was shown that lesions, caused by $6-\mathrm{OHDA}$ in the $\mathrm{SN}_{\mathrm{pc}}$, resulted in motor deficits over time $(+3$ weeks after injection) especially with a cell loss greater than $70 \%$ (Iancu, et al., 2005). In our study, TH-staining confirmed degeneration of dopaminergic neurons well beyond this $70 \%$. Performance in the cylinder and Catwalk test confirm motor impairment of the limbs contralateral to the lesion, as reported previously in 6-OHDA PD models (Hajj, et al., 2015,Monville, et al., 2006,Vandeputte, et al., 2010). Results from the Catwalk indicate a disturbance of the normal step sequence and a decreased velocity when moving the contralateral limbs during the swing phase. This phenotype is in accordance to symptoms of PD patients which present with a shuffling gait, decreased overall velocity and a higher number of erroneous step sequences when walking (Morris, et al., 1994,Morris, et al., 1996,Sidaway, et al., 2006). Animals presenting with LID also depicted significant motor impairment (detected in the Catwalk test and AIMS). AIM scores were in line with findings of Putterman and colleagues, who validated LID development in the 6-OHDA PD model, and investigated the effect of various LDOPA doses (Putterman, et al., 2007). Rats developed LID at variable time points during L-DOPA treatment, as seen in patients, which confirms the translational validity of this model. Also, the degree and time point at which LID development occurs, does depend on the site of the lesion, as MFB lesions were shown to generate LID more quickly, and at a lower L-DOPA dose than the intranigral lesions we used (Lundblad, et al., 2004).

Remarkably, we found a positive connection between severity of dyskinesia (expressed in AIM scores) and mGluR5 availability, in agreement with MPTP-primate studies (Samadi, et al., 2008,Sanchez-Pernaute, et al., 2008). In these primate studies, animals were treated for longer periods ( 1 month) with dosages until 5 times higher compared to our study. It is thus plausible that mGluR5 levels are only upregulated during severe LID, suggesting that an extended treatment period could have led to mGluR5 upregulation in the basal ganglia, as implied by a positive correlation with AIMS.

In conclusion, this study indicates significantly decreased mGlu5 receptor availability, focused in the ipsilateral caudate-putamen of PD rats, while L-DOPA treatment led to increased mGluR5 availability in the motor- and somatosensory cortex in vivo. Voxel-based analysis of $\left[{ }^{18} \mathrm{~F}\right] \mathrm{FPEB}$ binding points to a predominant involvement of the ipsilateral caudate-putamen, but also motor-associated regions such as the motor- and somatosensory cortex, at an early time point after dopaminergic degeneration in the $\mathrm{SN}_{\mathrm{pc}}$. In addition, mGluR5 levels were found positively correlated with LID severity, upon 2 weeks of L-DOPA therapy. ${ }^{1} \mathrm{H}-\mathrm{MRS}$ did not indicate altered glutamate concentrations in the caudate-putamen of PD rats with or without dyskinesia. However, 
glutamine concentrations were found to be higher in the contralateral compared to the ipsilateral caudateputamen at week 5, most likely indicating a treatment-independent effect.

\section{ACKNOWLEDGEMENTS}

We thank Tinne Buelens and Ann Van Santvoort for their technical support and Annelies Aertgeerts for performing the stereotactic surgery. This work was supported by the the European Commission, FP7, INMiND [grant agreement no. 278850]. Melissa Crabbé is a fellow of the Research Foundation Flanders. Cindy Casteels and Anke Van der Perren are supported by a postdoctoral mandate of the Research Foundation Flanders, and Koen Van Laere is senior clinical investigator of the Research Foundation Flanders.

\section{CONFLICT OF INTEREST}

The authors declare that they have no conflict of interest.

\section{FIGURE LEGENDS}

\section{Figure 1:}

Experiment timeline (A-B). (A) Experiment timeline indicating functional imaging (PET), glutamate/glutamine quantification (MRS), and behavioral tests conducted in 6-OHDA-lesioned rats and upon development of levodopa-induced dyskinesia. (B) A detailed description of time points at which behavioral tests were conducted during saline and L-DOPA treatment. Abbreviations: 6-OHDA, 6-hydroxydopamine; AIMS, abnormal involuntary movement score; d, day; EPM, elevated plus maze; MRS, magnetic resonance spectroscopy; NORT: novel object recognition test; PET, positron emission tomography; SPT: sucrose preference test; w, week.

\section{Figure 2:}

Validation of the 6-OHDA rat PD model (A-B). (A) Cylinder test evaluating limb-use asymmetry of 6-OHDAlesioned PD and sham animals. PD animals present significant forelimb-use asymmetry compared to sham controls, indicating unilateral dopaminergic degeneration. (B) Immunohistochemical staining of the tyrosine hydroxylase (TH) enzyme in the substantia nigra. A clear unilateral degeneration of TH-expressing dopaminergic neurons is present in 6-OHDA-lesioned animals, but not in saline-injected control animals. 


\section{Figure 3:}

Average orthogonal $\left[{ }^{18} \mathrm{~F}\right]$-FPEB $\mathrm{BP}_{\mathrm{ND}}$ in $(\mathbf{A})$ drug-naïve $\mathrm{PD}$ rats $(\mathrm{n}=18)$, and $(\mathbf{B})$ Parkinsonian rats upon LDOPA treatment $(n=10)$, in comparison to their corresponding control conditions (sham: $n=9$; saline: $n=10)$. Note the decreased $\left[{ }^{18} \mathrm{~F}\right] \mathrm{FPEB}$ binding in the ipsilateral caudate-putamen of 6-OHDA-lesioned rats, as visible in section A. The intersection point has been set to the mid-caudate-putamen in the lesioned hemisphere. Color bars indicate $\mathrm{BP}_{\mathrm{ND}}$ values for the radioligand. $\mathrm{L}=$ left; $\mathrm{R}=$ right.

\section{Figure 4:}

$\left[{ }^{18} \mathrm{~F}\right]$ FPEB binding in 6-OHDA-lesioned PD rats. Coronal brain sections overlaid with functional T-maps indicating significantly decreased mGluR5 $\mathrm{BP}_{\mathrm{ND}}$ at $\mathrm{p}_{\text {height }}<0.005(\mathbf{A})$ and $<0.001(\mathbf{B})$ in PD rats $(\mathrm{n}=18)$, as compared to control rats $(\mathrm{n}=9)$ at 3 weeks post-injection. Voxel-based analysis demonstrated decreased $\left[{ }^{18}\right.$ F]FPEB binding in the bilateral caudate-putamen, ipsilateral motor-and somatosensory cortex, and the contralateral somatosensory and parietal association cortex of PD rats, as compared to controls. Significant clusters are indicated using a T-statistic color scale which shows significance at the voxel level. $(\mathrm{R}=\mathrm{right} ; \mathrm{L}=$ left).

\section{Figure 5:}

Relative $\left[{ }^{18} \mathrm{~F}\right] \mathrm{FPEB}$ uptake in L-DOPA-treated PD rats. Brains sections show overlays of T-maps on the region with significantly increased mGluR5 binding in 6-OHDA-lesioned PD rats, treated with L-DOPA for 2 weeks (n $=10)$, as compared to saline-treated animals $(\mathrm{n}=10)$ at 5 weeks post-injection. The intersection point is set to the Paxinos coordinate peak max, that is, the left (contralateral) motor- and somatosensory cortex. A T-statistic color scale indicates significance of the cluster at the voxel level. Image shown in neurological convention. $(\mathrm{R}=$ right; $\mathrm{L}=$ left)

\section{Figure 6:}

MRI-guided ${ }^{1} \mathrm{H}-\mathrm{MRS}$. (A) Averaged ${ }^{1} \mathrm{H}-\mathrm{MRS}$ spectrum of the ipsilateral caudate-putamen of drug-naïve 6OHDA-lesioned rats, 3 weeks after injection. (B-C) Bar charts of glutamine concentration (mmol/ $\mathrm{kg}$ ) in the 6OHDA-lesioned (ipsilateral; black) and contralateral (white) caudate-putamen. No significant differences were detected between PD rats $(n=20)$ and controls $(n=10 ; B)$ whereas concentrations were found significantly 
decreased in the ipsilateral caudate-putamen of levodopa-treated- $(\mathrm{n}=10)$ as well as saline-treated rats $(\mathrm{n}=10$; C). ${ }^{* *} \mathrm{p}<0.01 ;$ Wilcoxon Log-Rank test. Data are indicated as mean $\pm \mathrm{SD}$.

\section{Figure 7:}

Behavioral outcomes in drug-naïve (A, D, E) and L-DOPA-treated PD rats (B, C, F). (A-C) Motor coordination and balance of drug-naïve and L-DOPA-treated PD rats in the catwalk test (A) Effect of 6-OHDA lesion on motor performance in the Catwalk test. Lesioning significantly lowered swing speed of the contralateral front and hind paws. (B-C) L-DOPA administration led to a significantly higher duty cycle of the hind paws and increased diagonal support. (D) Place preference in the elevated plus maze. PD rats showed a significant preference for the closed arm in comparison to the open arm, suggesting an increase in anxious behavior. Differences with the sham group were however not significant. (E) Evaluation of short-term memory. Time spent with familiar (object A) or unfamiliar objects after short-term exposure (object B) estimates the capacity of the animal to retain short-term information. Lesioning significantly affects short-term memory. (F) AIM scores upon day 15 of L-DOPA treatment. Parkinsonian rats were treated with $6 \mathrm{mg} / \mathrm{kg} \mathrm{L}$-DOPA and $12.5 \mathrm{mg} / \mathrm{kg}$ benserazide (squares) or saline (circles). Asterisks show time points at which AIM scores were significantly different between L-DOPA- and saline-treated animals. ${ }^{* *} \mathrm{p}<0.01$; ${ }^{* * *} \mathrm{p}<0.001$; Mann-Whitney U test for AB and D-F. Wilcoxon Signed-Rank test for C. Significances were retained after correction for multiple testing. Controls $n=10, P D n=20$, L-DOPA $n=10$. Data are shown as mean \pm SD.

\section{Figure 8:}

VOI-based correlation analysis. Scatter plot of VOI-based correlation analysis in 6-OHDA-lesioned PD rats with dyskinesia, indicating a positive correlation of total AIM score to relative $\left[{ }^{18} \mathrm{~F}\right] \mathrm{FPEB}$ uptake in the ipsilateral caudate-putamen, at day 15 of L-DOPA treatment. Correlation performed using Spearman's rank test. 


\section{TABLES}

\section{Table 1:}

Peak locations for clusters of group comparisons and correlation analysis at $\mathrm{p}_{\text {height }} \leq 0.005$ uncorrected, $\mathrm{K}_{\mathrm{e}}>200$.

\begin{tabular}{|c|c|c|c|c|c|c|c|c|c|}
\hline & \multicolumn{2}{|c|}{ Cluster-level } & \multicolumn{3}{|c|}{ Voxel-level } & \multicolumn{3}{|c|}{ Structure } & \multirow[t]{2}{*}{ Name } \\
\hline & $\mathrm{p}_{\text {corr }}$ & $k_{E}$ & $\mathrm{~T}$ & $\mathrm{p}_{\text {uncorr }}$ & $\begin{array}{c}\text { Intensity difference } \\
(\%)\end{array}$ & $x$ & y & z & \\
\hline \multicolumn{10}{|c|}{ Absolute $\left[{ }^{18}\right.$ F]FPEB images } \\
\hline \multicolumn{10}{|c|}{ Cross-sectional $\left[{ }^{18}\right]$ FPEB analysis } \\
\hline \multirow[t]{4}{*}{ sham $>$ PD } & $<0.001$ & 27069 & 5.19 & $<0.001$ & $-12.0 \pm 3.5$ & 5.8 & -3.8 & -5.4 & \multirow{3}{*}{$\begin{array}{l}\text { Bilateral caudate-putamen } \\
\text { and somatosensory cortex, } \\
\text { ipsilateral motor cortex, and } \\
\text { contralateral parietal } \\
\text { association cortex }\end{array}$} \\
\hline & & & 4.90 & $<0.001$ & & -3.2 & 0.4 & -5.0 & \\
\hline & & & 4.73 & $<0.001$ & & -2.0 & 1.4 & -4.8 & \\
\hline & \multicolumn{9}{|c|}{ Relative $\left[{ }^{18}\right.$ F]FPEB images } \\
\hline \multicolumn{10}{|c|}{ Cross-sectional $\left[{ }^{18}\right]$ FPEB analysis } \\
\hline sham > PD & 0.346 & 406 & 5.54 & $<0.001$ & $-14.9 \pm 1.1$ & -4.6 & -0.6 & -5.2 & \multirow{3}{*}{$\begin{array}{l}\text { Ipsilateral caudate-putamen } \\
\text { and somatosensory cortex }\end{array}$} \\
\hline & & & 3.72 & 0.001 & & -5.4 & -2.4 & -4.0 & \\
\hline & & & 3.26 & 0.002 & & -5.2 & -1.0 & -2.8 & \\
\hline \multicolumn{10}{|c|}{ Flexible factorial $\left[{ }^{18}\right.$ F]FPEB analysis } \\
\hline Saline $\Delta(5 w k-3 w k)<L-$ & 0.325 & 225 & 4.45 & $<0.001$ & $+7.6 \pm 6.2$ & -4.4 & 1.8 & -3.4 & \multirow{2}{*}{$\begin{array}{l}\text { Contralateral motor and } \\
\text { somatosensory cortex }\end{array}$} \\
\hline DOPA therapy $\Delta(5 w k-3 w k)$ & & & 4.17 & $<0.001$ & & -3.8 & 2.4 & -4.2 & \\
\hline
\end{tabular}

$\mathrm{p}_{\text {corr }}$ at cluster level: chance $(\mathrm{p})$ of finding cluster with this or a greater size $\left(\mathrm{K}_{\mathrm{e}}\right)$, corrected for the investigated volume; $\mathrm{K}_{\mathrm{e}}$ : cluster extent; $\mathrm{T}$ : parameter for statistical significance; $\mathrm{p}_{\text {uncorr }}$ at voxel level: the chance (p) of discovering (under the null hypothesis) a voxel this or greater height (T-statistic), uncorrected for the investigated volume; $\%$ intensity difference at the voxel level of (L-DOPA-treated) PD rats in comparison to controls; $\mathrm{x}$ : lateral distance from the midline (millimeter); y: anteroposterior position relative to the interaural line; $\mathrm{z}$ : dorsoventral position relative to the Bregma (based on the Paxinos stereotactic atlas). 


\section{REFERENCES}

Abe, T., Sugihara, H., Nawa, H., Shigemoto, R., Mizuno, N., Nakanishi, S. 1992. Molecular characterization of a novel metabotropic glutamate receptor mGluR5 coupled to inositol phosphate/Ca2+ signal transduction. The Journal of biological chemistry 267(19), 13361-8.

Baekelandt, V., Claeys, A., Eggermont, K., Lauwers, E., De Strooper, B., Nuttin, B., Debyser, Z. 2002. Characterization of lentiviral vector-mediated gene transfer in adult mouse brain. Human gene therapy 13(7), 841-53. doi:10.1089/10430340252899019.

Battaglia, G., Busceti, C.L., Molinaro, G., Biagioni, F., Storto, M., Fornai, F., Nicoletti, F., Bruno, V. 2004. Endogenous activation of mGlu5 metabotropic glutamate receptors contributes to the development of nigro-striatal damage induced by 1-methyl-4phenyl-1,2,3,6-tetrahydropyridine in mice. The Journal of neuroscience : the official journal of the Society for Neuroscience 24(4), 828-35. doi:10.1523/JNEUROSCI.3831-03.2004.

Bezard, E., Brotchie, J.M., Gross, C.E. 2001. Pathophysiology of levodopa-induced dyskinesia: potential for new therapies. Nature reviews Neuroscience 2(8), 577-88. doi:10.1038/35086062.

Bezard, E., Pioli, E.Y., Li, Q., Girard, F., Mutel, V., Keywood, C., Tison, F., Rascol, O., Poli, S.M. 2014. The mGluR5 negative allosteric modulator dipraglurant reduces dyskinesia in the MPTP macaque model. Movement disorders : official journal of the Movement Disorder Society 29(8), 1074-9. doi:10.1002/mds.25920.

Branchi, I., D'Andrea, I., Armida, M., Carnevale, D., Ajmone-Cat, M.A., Pezzola, A., Potenza, R.L., Morgese, M.G., Cassano, T., Minghetti, L., Popoli, P., Alleva, E. 2010. Striatal 6-OHDA lesion in mice: Investigating early neurochemical changes underlying Parkinson's disease. Behavioural brain research 208(1), 137-43. doi:10.1016/j.bbr.2009.11.020.

Breysse, N., Amalric, M., Salin, P. 2003. Metabotropic glutamate 5 receptor blockade alleviates akinesia by normalizing activity of selective basal-ganglia structures in parkinsonian rats. The Journal of neuroscience : the official journal of the Society for Neuroscience 23(23), 8302-9.

Byrnes, K.R., Stoica, B., Loane, D.J., Riccio, A., Davis, M.I., Faden, A.I. 2009. Metabotropic glutamate receptor 5 activation inhibits microglial associated inflammation and neurotoxicity. Glia 57(5), 550-60. doi:10.1002/glia.20783.

Carvalho, M.M., Campos, F.L., Coimbra, B., Pego, J.M., Rodrigues, C., Lima, R., Rodrigues, A.J., Sousa, N., Salgado, A.J. 2013. Behavioral characterization of the 6hydroxidopamine model of Parkinson's disease and pharmacological rescuing of nonmotor deficits. Molecular neurodegeneration 8, 14. doi:10.1186/1750-1326-8-14.

Casteels, C., Vermaelen, P., Nuyts, J., Van Der Linden, A., Baekelandt, V., Mortelmans, L., Bormans, G., Van Laere, K. 2006. Construction and evaluation of multitracer smallanimal PET probabilistic atlases for voxel-based functional mapping of the rat brain. Journal of nuclear medicine : official publication, Society of Nuclear Medicine 47(11), 1858-66.

Castellano, M.A., Rodriguez Diaz, M. 1991. Nigrostriatal dopaminergic cell activity is under control by substantia nigra of the contralateral brain side: electrophysiological evidence. Brain research bulletin 27(2), 213-8.

Cenci, M.A., Lundblad, M. 2006. Post- versus presynaptic plasticity in L-DOPA-induced dyskinesia. Journal of neurochemistry 99(2), 381-92. doi:10.1111/j.14714159.2006.04124.x. 
Chase, T.N., Oh, J.D. 2000. Striatal dopamine- and glutamate-mediated dysregulation in experimental parkinsonism. Trends in neurosciences 23(10 Suppl), S86-91.

Clarke, C.E., Lowry, M., Horsman, A. 1997. Unchanged basal ganglia N-acetylaspartate and glutamate in idiopathic Parkinson's disease measured by proton magnetic resonance spectroscopy. Movement disorders : official journal of the Movement Disorder Society 12(3), 297-301. doi:10.1002/mds.870120306.

Conn, P.J., Battaglia, G., Marino, M.J., Nicoletti, F. 2005. Metabotropic glutamate receptors in the basal ganglia motor circuit. Nature reviews Neuroscience 6(10), 787-98. doi:10.1038/nrn1763.

Conn, P.J., Pin, J.P. 1997. Pharmacology and functions of metabotropic glutamate receptors. Annual review of pharmacology and toxicology 37, 205-37. doi:10.1146/annurev.pharmtox.37.1.205.

Coune, P.G., Craveiro, M., Gaugler, M.N., Mlynarik, V., Schneider, B.L., Aebischer, P., Gruetter, R. 2013. An in vivo ultrahigh field 14.1 T (1) H-MRS study on 6-OHDA and alpha-synuclein-based rat models of Parkinson's disease: GABA as an early disease marker. NMR in biomedicine 26(1), 43-50. doi:10.1002/nbm.2817.

de Laat, B., Leurquin-Sterk, G., Celen, S., Bormans, G., Koole, M., Van Laere, K., Casteels, C. 2015. Preclinical Evaluation and Quantification of 18F-FPEB as a Radioligand for PET Imaging of the Metabotropic Glutamate Receptor 5. Journal of nuclear medicine : official publication, Society of Nuclear Medicine 56(12), 1954-9. doi:10.2967/jnumed.115.162636.

Duvoisin, R.C. 1974. Variations in the "on-off" phenomenon. Advances in neurology 5, 33940.

Fahn, S. 1974. "On-off" phenomenon with levodopa therapy in Parkinsonism. Clinical and pharmacologic correlations and the effect of intramuscular pyridoxine. Neurology 24(5), 431-41.

Fuxe, K., Agnati, L.F., Jacobsen, K., Hillion, J., Canals, M., Torvinen, M., Tinner-Staines, B., Staines, W., Rosin, D., Terasmaa, A., Popoli, P., Leo, G., Vergoni, V., Lluis, C., Ciruela, F., Franco, R., Ferre, S. 2003. Receptor heteromerization in adenosine A2A receptor signaling: relevance for striatal function and Parkinson's disease. Neurology 61(11 Suppl 6), S19-23.

Haas, S.J., Zhou, X., Machado, V., Wree, A., Krieglstein, K., Spittau, B. 2016. Expression of Tgfbeta1 and Inflammatory Markers in the 6-hydroxydopamine Mouse Model of Parkinson's Disease. Frontiers in molecular neuroscience 9, 7. doi:10.3389/fnmol.2016.00007.

Hajj, R., Milet, A., Toulorge, D., Cholet, N., Laffaire, J., Foucquier, J., Robelet, S., Mitry, R., Guedj, M., Nabirotchkin, S., Chumakov, I., Cohen, D. 2015. Combination of acamprosate and baclofen as a promising therapeutic approach for Parkinson's disease. Scientific reports 5, 16084. doi:10.1038/srep16084.

Hu, M.T., Taylor-Robinson, S.D., Chaudhuri, K.R., Bell, J.D., Labbe, C., Cunningham, V.J., Koepp, M.J., Hammers, A., Morris, R.G., Turjanski, N., Brooks, D.J. 2000. Cortical dysfunction in non-demented Parkinson's disease patients: a combined (31)P-MRS and (18)FDG-PET study. Brain : a journal of neurology 123 ( Pt 2), 340-52.

Iancu, R., Mohapel, P., Brundin, P., Paul, G. 2005. Behavioral characterization of a unilateral 6-OHDA-lesion model of Parkinson's disease in mice. Behavioural brain research 162(1), 1-10. doi:10.1016/j.bbr.2005.02.023.

Jenkins, B., Zhu, A., Poutiainen, P., Choi, J.K., Kil, K.E., Zhang, Z., Kuruppu, D., Aytan, N., Dedeoglu, A., Brownell, A.L. 2015. Functional modulation of G-protein coupled receptors during Parkinson disease-like neurodegeneration. Neuropharmacology. doi:10.1016/j.neuropharm.2015.11.010. 
Jenner, P. 2000. Factors influencing the onset and persistence of dyskinesia in MPTP-treated primates. Annals of neurology 47(4), S90-S104.

Jong, Y.J., Kumar, V., O'Malley, K.L. 2009. Intracellular metabotropic glutamate receptor 5 (mGluR5) activates signaling cascades distinct from cell surface counterparts. The Journal of biological chemistry 284(51), 35827-38. doi:10.1074/jbc.M109.046276.

Kaasinen, V., Ruottinen, H.M., Nagren, K., Lehikoinen, P., Oikonen, V., Rinne, J.O. 2000. Upregulation of putaminal dopamine D2 receptors in early Parkinson's disease: a comparative PET study with [11C] raclopride and [11C]N-methylspiperone. Journal of nuclear medicine : official publication, Society of Nuclear Medicine 41(1), 65-70.

Kanamatsu, T., Otsuki, T., Tokuno, H., Nambu, A., Takada, M., Okamoto, K., Watanabe, H., Umeda, M., Tsukada, Y. 2007. Changes in the rates of the tricarboxylic acid (TCA) cycle and glutamine synthesis in the monkey brain with hemiparkinsonism induced by intracarotid infusion of 1-methyl-4-phenyl-1,2,3,6-tetrahydropyridine (MPTP): studies by non-invasive 13C-magnetic resonance spectroscopy. Brain research 1181, 142-8. doi:10.1016/j.brainres.2007.08.051.

Kickler, N., Krack, P., Fraix, V., Lebas, J.F., Lamalle, L., Durif, F., Krainik, A., Remy, C., Segebarth, C., Pollak, P. 2007. Glutamate measurement in Parkinson's disease using MRS at $3 \mathrm{~T}$ field strength. NMR in biomedicine 20(8), 757-62. doi:10.1002/nbm.1141.

Lundblad, M., Andersson, M., Winkler, C., Kirik, D., Wierup, N., Cenci, M.A. 2002. Pharmacological validation of behavioural measures of akinesia and dyskinesia in a rat model of Parkinson's disease. The European journal of neuroscience 15(1), 120-32.

Lundblad, M., Picconi, B., Lindgren, H., Cenci, M.A. 2004. A model of L-DOPA-induced dyskinesia in 6-hydroxydopamine lesioned mice: relation to motor and cellular parameters of nigrostriatal function. Neurobiology of disease 16(1), 110-23. doi:10.1016/j.nbd.2004.01.007.

Ma, S.Y., Roytta, M., Rinne, J.O., Collan, Y., Rinne, U.K. 1997. Correlation between neuromorphometry in the substantia nigra and clinical features in Parkinson's disease using disector counts. Journal of the neurological sciences 151(1), 83-7.

Marsden, C.D., Parkes, J.D. 1976. "On-off" effects in patients with Parkinson's disease on chronic levodopa therapy. Lancet 1(7954), 292-6.

Monville, C., Torres, E.M., Dunnett, S.B. 2006. Comparison of incremental and accelerating protocols of the rotarod test for the assessment of motor deficits in the 6-OHDA model. Journal of neuroscience methods 158(2), 219-23. doi:10.1016/j.jneumeth.2006.06.001.

Morgan, S., Huston, J.P. 1990. The interhemispheric projection from the substantia nigra to the caudate-putamen as depicted by the anterograde transport of [3H]leucine. Behavioural brain research 38(2), 155-62.

Morin, N., Jourdain, V.A., Morissette, M., Gregoire, L., Di Paolo, T. 2014. Long-term treatment with 1-DOPA and an mGlu5 receptor antagonist prevents changes in brain basal ganglia dopamine receptors, their associated signaling proteins and neuropeptides in parkinsonian monkeys. Neuropharmacology 79, 688-706. doi:10.1016/j.neuropharm.2014.01.014.

Morris, M.E., Iansek, R., Matyas, T.A., Summers, J.J. 1994. The pathogenesis of gait hypokinesia in Parkinson's disease. Brain : a journal of neurology 117 ( Pt 5), 116981.

Morris, M.E., Matyas, T.A., Iansek, R., Summers, J.J. 1996. Temporal stability of gait in Parkinson's disease. Physical therapy 76(7), 763-77; discussion 78-80. 
Nevalainen, N., Lundblad, M., Gerhardt, G.A., Stromberg, I. 2013. Striatal glutamate release in L-DOPA-induced dyskinetic animals. PloS one 8(2), e55706. doi:10.1371/journal.pone.0055706.

Niethammer, M., Tang, C.C., Ma, Y., Mattis, P.J., Ko, J.H., Dhawan, V., Eidelberg, D. 2013. Parkinson's disease cognitive network correlates with caudate dopamine. NeuroImage 78, 204-9. doi:10.1016/j.neuroimage.2013.03.070.

Obeso, J.A., Grandas, F., Vaamonde, J., Luquin, M.R., Artieda, J., Lera, G., Rodriguez, M.E., Martinez-Lage, J.M. 1989. Motor complications associated with chronic levodopa therapy in Parkinson's disease. Neurology 39(11 Suppl 2), 11-9.

Ossowska, K., Konieczny, J., Wardas, J., Pietraszek, M., Kuter, K., Wolfarth, S., Pilc, A. 2007. An influence of ligands of metabotropic glutamate receptor subtypes on parkinsonian-like symptoms and the striatopallidal pathway in rats. Amino acids 32(2), 179-88. doi:10.1007/s00726-006-0317-y.

Ouattara, B., Gasparini, F., Morissette, M., Gregoire, L., Samadi, P., Gomez-Mancilla, B., Di Paolo, T. 2010. Effect of L-Dopa on metabotropic glutamate receptor 5 in the brain of parkinsonian monkeys. Journal of neurochemistry 113(3), 715-24. doi:10.1111/j.14714159.2010.06635.x.

Ouattara, B., Gregoire, L., Morissette, M., Gasparini, F., Vranesic, I., Bilbe, G., Johns, D.R., Rajput, A., Hornykiewicz, O., Rajput, A.H., Gomez-Mancilla, B., Di Paolo, T. 2011. Metabotropic glutamate receptor type 5 in levodopa-induced motor complications. Neurobiology of aging 32(7), 1286-95. doi:10.1016/j.neurobiolaging.2009.07.014.

Pierucci, M., Di Matteo, V., Benigno, A., Crescimanno, G., Esposito, E., Di Giovanni, G. 2009. The unilateral nigral lesion induces dramatic bilateral modification on rat brain monoamine neurochemistry. Annals of the New York Academy of Sciences 1155, 316-23. doi:10.1111/j.1749-6632.2008.03679.x.

Putterman, D.B., Munhall, A.C., Kozell, L.B., Belknap, J.K., Johnson, S.W. 2007. Evaluation of levodopa dose and magnitude of dopamine depletion as risk factors for levodopainduced dyskinesia in a rat model of Parkinson's disease. The Journal of pharmacology and experimental therapeutics 323(1), 277-84. doi:10.1124/jpet.107.126219.

Robelet, S., Melon, C., Guillet, B., Salin, P., Kerkerian-Le Goff, L. 2004. Chronic L-DOPA treatment increases extracellular glutamate levels and GLT1 expression in the basal ganglia in a rat model of Parkinson's disease. The European journal of neuroscience 20(5), 1255-66. doi:10.1111/j.1460-9568.2004.03591.x.

Rodriguez, M., Castellano, M.A., Palarea, M.D. 1990. Interhemispheric regulation of dopaminergic ascending systems. Life sciences 47(5), 377-84.

Romano, C., Sesma, M.A., McDonald, C.T., O'Malley, K., Van den Pol, A.N., Olney, J.W. 1995. Distribution of metabotropic glutamate receptor mGluR5 immunoreactivity in rat brain. The Journal of comparative neurology 355(3), 455-69. doi:10.1002/cne.903550310.

Rylander, D., Iderberg, H., Li, Q., Dekundy, A., Zhang, J., Li, H., Baishen, R., Danysz, W., Bezard, E., Cenci, M.A. 2010. A mGluR5 antagonist under clinical development improves L-DOPA-induced dyskinesia in parkinsonian rats and monkeys. Neurobiology of disease 39(3), 352-61. doi:10.1016/j.nbd.2010.05.001.

Samadi, P., Gregoire, L., Morissette, M., Calon, F., Hadj Tahar, A., Dridi, M., Belanger, N., Meltzer, L.T., Bedard, P.J., Di Paolo, T. 2008. mGluR5 metabotropic glutamate receptors and dyskinesias in MPTP monkeys. Neurobiology of aging 29(7), 1040-51. doi:10.1016/j.neurobiolaging.2007.02.005.

Sanchez-Pernaute, R., Wang, J.Q., Kuruppu, D., Cao, L., Tueckmantel, W., Kozikowski, A., Isacson, O., Brownell, A.L. 2008. Enhanced binding of metabotropic glutamate 
receptor type 5 (mGluR5) PET tracers in the brain of parkinsonian primates. NeuroImage 42(1), 248-51. doi:10.1016/j.neuroimage.2008.04.170.

Scherfler, C., Khan, N.L., Pavese, N., Lees, A.J., Quinn, N.P., Brooks, D.J., Piccini, P.P. 2006. Upregulation of dopamine D2 receptors in dopaminergic drug-naive patients with Parkin gene mutations. Movement disorders : official journal of the Movement Disorder Society 21(6), 783-8. doi:10.1002/mds.20811.

Shigemoto, R., Nomura, S., Ohishi, H., Sugihara, H., Nakanishi, S., Mizuno, N. 1993. Immunohistochemical localization of a metabotropic glutamate receptor, mGluR5, in the rat brain. Neuroscience letters 163(1), 53-7.

Sidaway, B., Anderson, J., Danielson, G., Martin, L., Smith, G. 2006. Effects of long-term gait training using visual cues in an individual with Parkinson disease. Physical therapy 86(2), 186-94.

Taylor-Robinson, S.D., Turjanski, N., Bhattacharya, S., Seery, J.P., Sargentoni, J., Brooks, D.J., Bryant, D.J., Cox, I.J. 1999. A proton magnetic resonance spectroscopy study of the striatum and cerebral cortex in Parkinson's disease. Metabolic brain disease 14(1), 45-55.

Tison, F., Keywood, C., Wakefield, M., Durif, F., Corvol, J.C., Eggert, K., Lew, M., Isaacson, S., Bezard, E., Poli, S.M., Goetz, C.G., Trenkwalder, C., Rascol, O. 2016. A Phase 2A Trial of the Novel mGluR5-Negative Allosteric Modulator Dipraglurant for Levodopa-Induced Dyskinesia in Parkinson's Disease. Movement disorders : official journal of the Movement Disorder Society. doi:10.1002/mds.26659.

Trenkwalder, C., Stocchi, F., Poewe, W., Dronamraju, N., Kenney, C., Shah, A., von Raison, F., Graf, A. 2016. Mavoglurant in Parkinson's patients with 1-Dopa-induced dyskinesias: Two randomized phase 2 studies. Movement disorders : official journal of the Movement Disorder Society 31(7), 1054-8. doi:10.1002/mds.26585.

Van der Perren, A., Toelen, J., Casteels, C., Macchi, F., Van Rompuy, A.S., Sarre, S., Casadei, N., Nuber, S., Himmelreich, U., Osorio Garcia, M.I., Michotte, Y., D'Hooge, R., Bormans, G., Van Laere, K., Gijsbers, R., Van den Haute, C., Debyser, Z., Baekelandt, V. 2015. Longitudinal follow-up and characterization of a robust rat model for Parkinson's disease based on overexpression of alpha-synuclein with adenoassociated viral vectors. Neurobiology of aging 36(3), 1543-58. doi:10.1016/j.neurobiolaging.2014.11.015.

Vandeputte, C., Taymans, J.M., Casteels, C., Coun, F., Ni, Y., Van Laere, K., Baekelandt, V. 2010. Automated quantitative gait analysis in animal models of movement disorders. BMC neuroscience 11, 92. doi:10.1186/1471-2202-11-92.

Zhu, A., Kil, K.-E., Kura, S., Gong, C., Zhang, Z., Choi, J.-K., Brownell, A.-L. 2013. Modulation of presynaptic (mGluR4) and postsynaptic (mGluR5) metabotropic glutamate receptors in 6-OHDA induced Parkinson's disease model. J NUCL MED MEETING ABSTRACTS 54(2_MeetingAbstracts), 524-.

Zhu, A., Wang, X., Yu, M., Wang, J.Q., Brownell, A.L. 2007. Evaluation of four pyridine analogs to characterize 6-OHDA-induced modulation of mGluR5 function in rat brain using microPET studies. Journal of cerebral blood flow and metabolism : official journal of the International Society of Cerebral Blood Flow and Metabolism 27(9), 1623-31. doi:10.1038/sj.jcbfm.9600461.

Zipp, F., Demisch, L., Derouiche, A., Fischer, P.A. 1998. Glutamine synthetase activity in patients with Parkinson's disease. Acta neurologica Scandinavica 97(5), 300-2.

Ziv, I., Zilkha-Falb, R., Offen, D., Shirvan, A., Barzilai, A., Melamed, E. 1997. Levodopa induces apoptosis in cultured neuronal cells--a possible accelerator of nigrostriatal degeneration in Parkinson's disease? Movement disorders : official journal of the Movement Disorder Society 12(1), 17-23. doi:10.1002/mds.870120105. 
Click here to download high resolution image

A

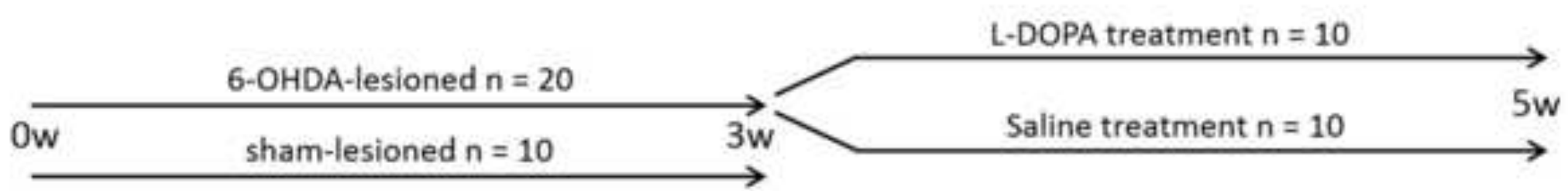

Stereotactic

surgery

B

Start L-DOPA or saline therapy AIMS

AIMS A

$1 d$
mGluR5 ([ [ ${ }^{18}$ F]FPEB)

${ }^{\mathrm{t}} \mathrm{H}$-MRS caudate-putamen

behavior

\section{mGluR5 ([ ${ }^{18}$ F]FPEB)}

${ }^{1} \mathrm{H}$-MRS caudate-putamen behavior

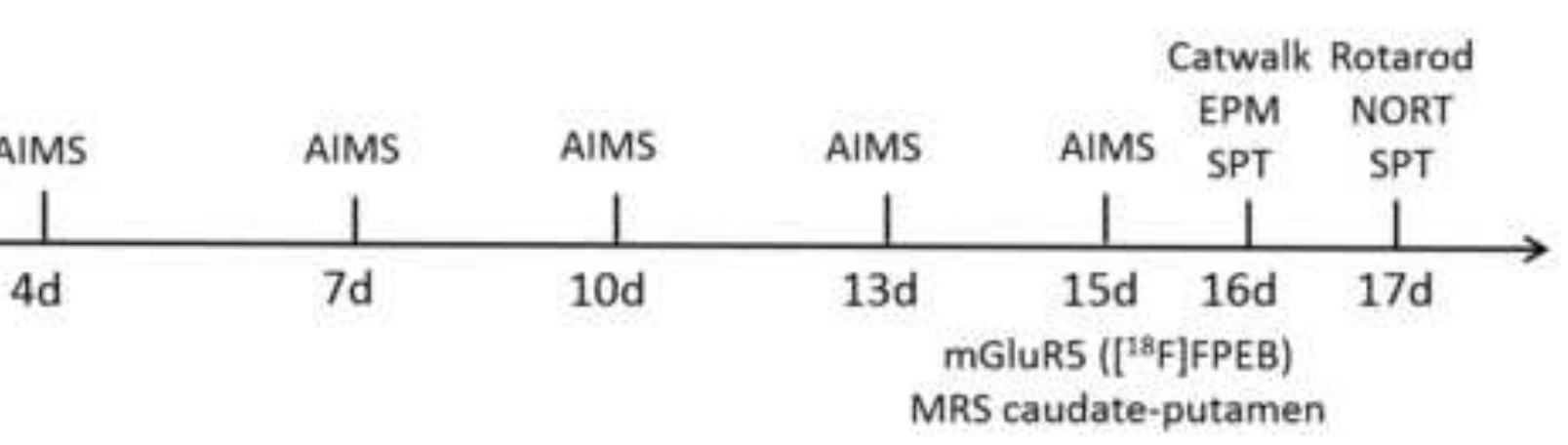


A

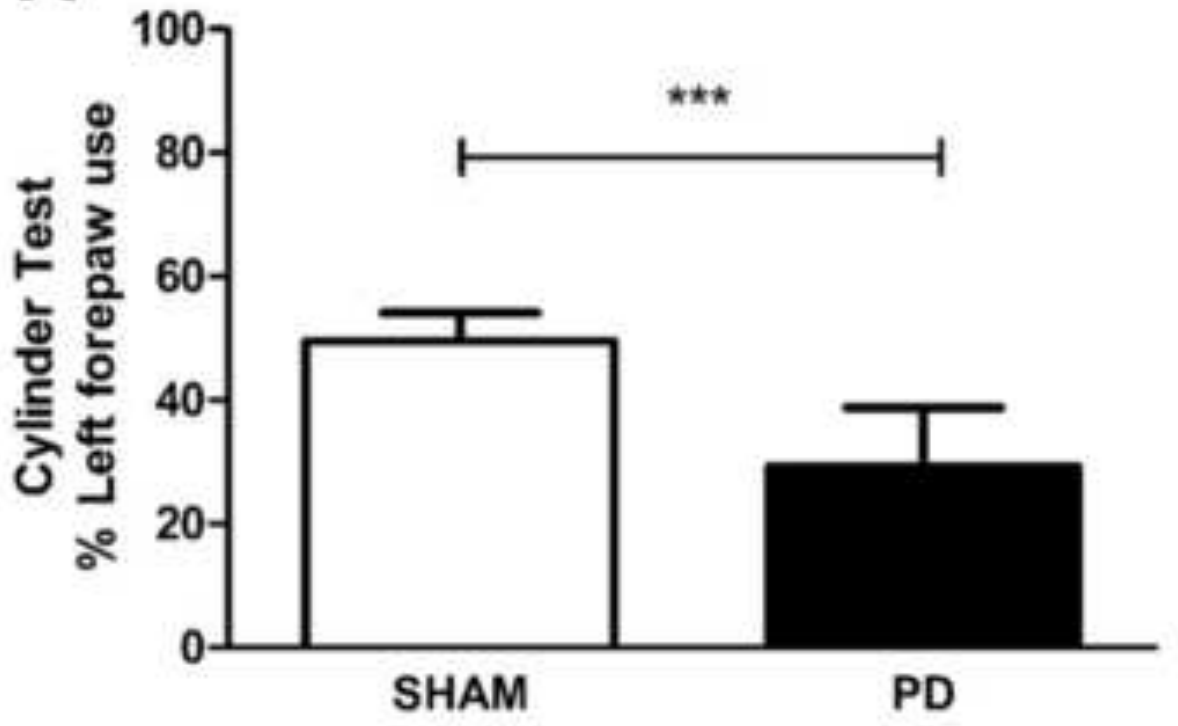

B

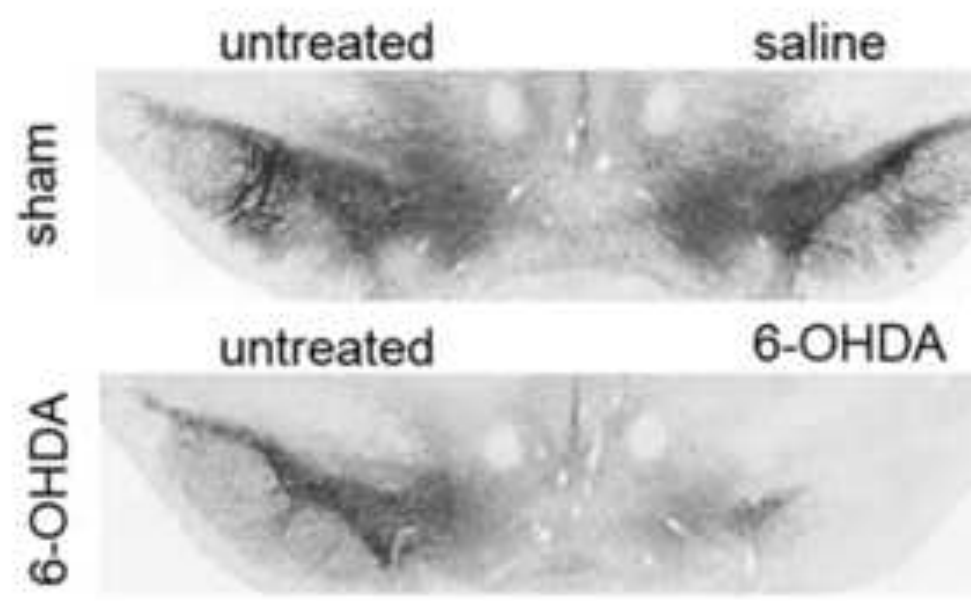




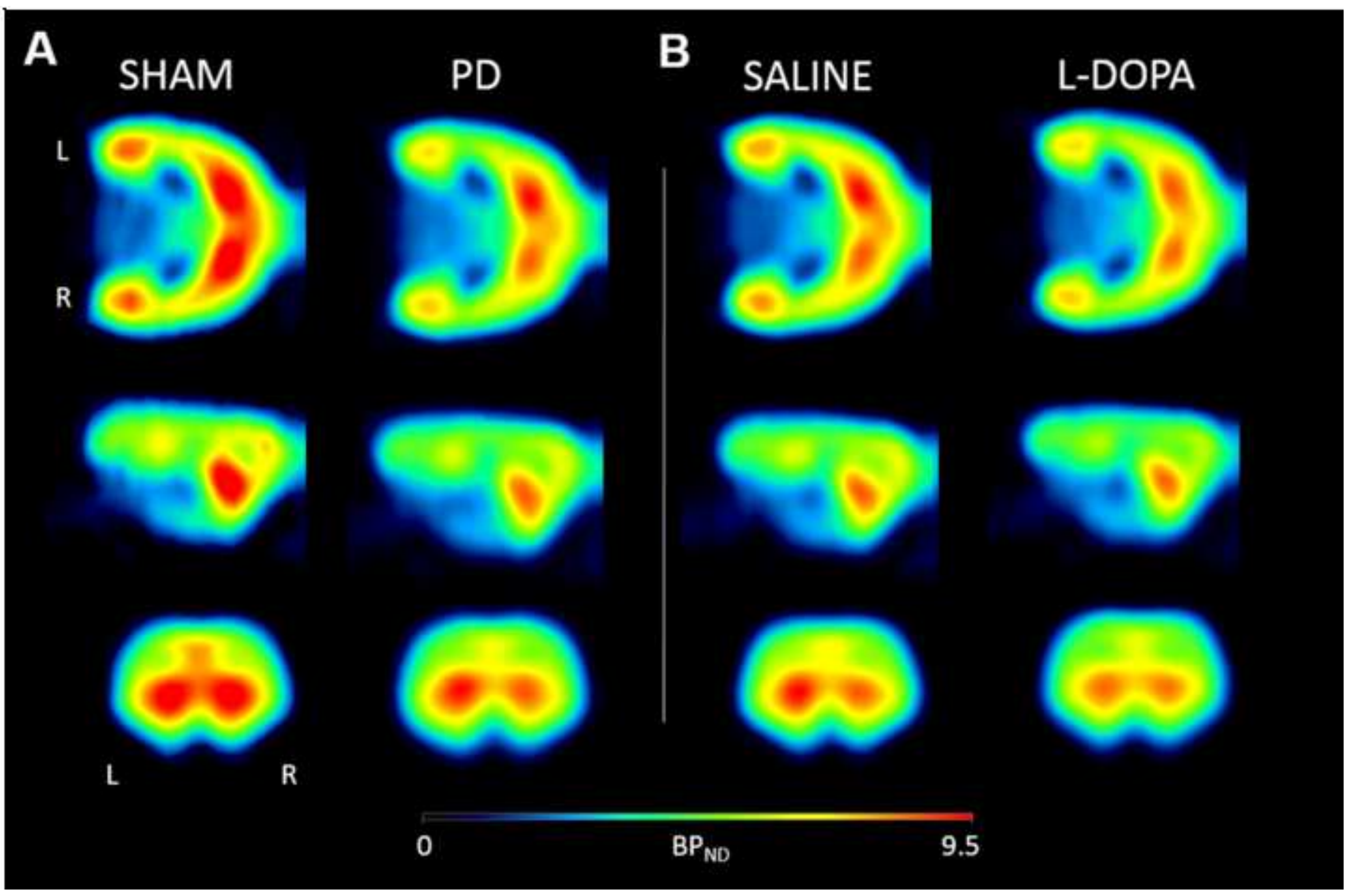




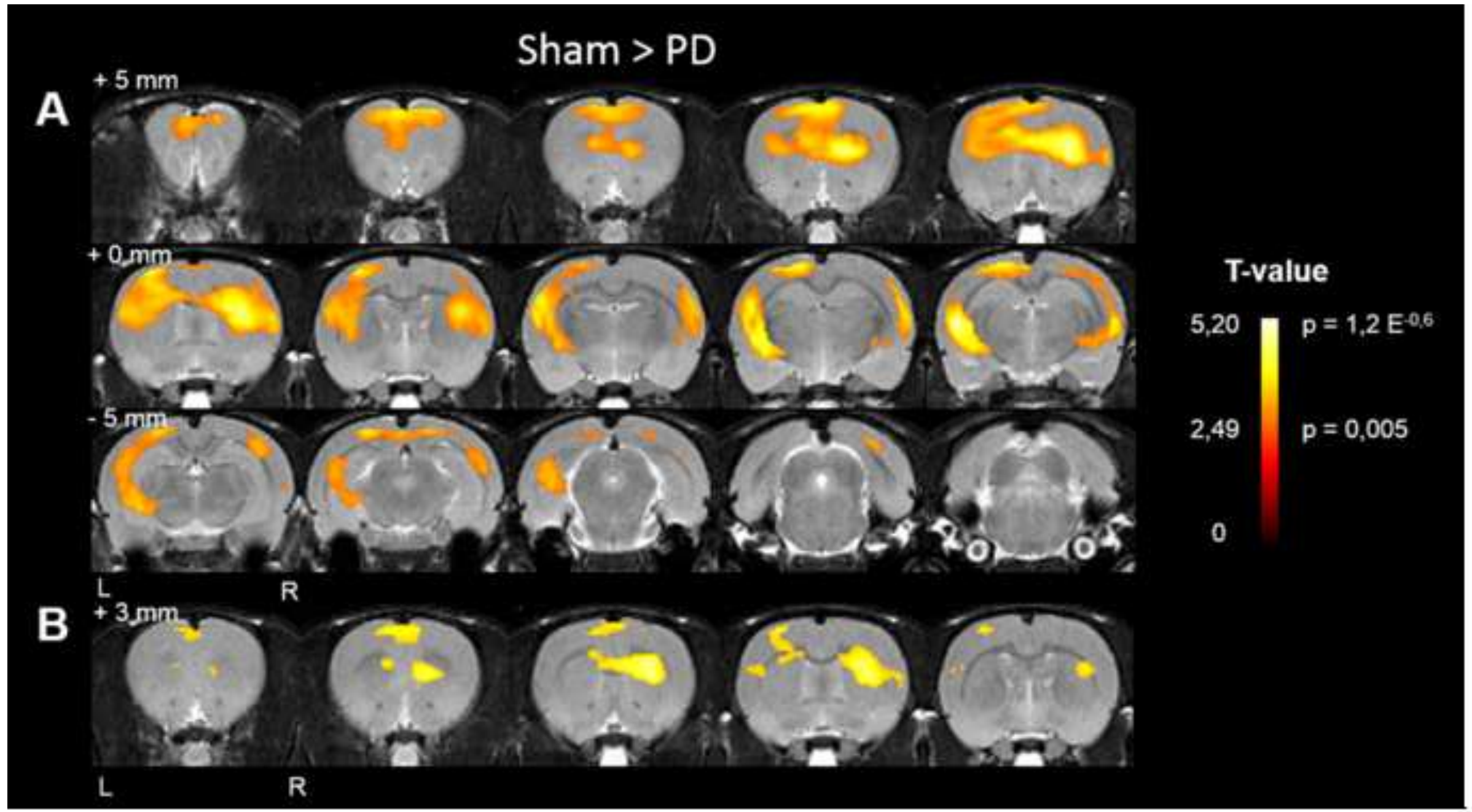

\section{Sham > PD}




\section{Saline < L-DOPA}
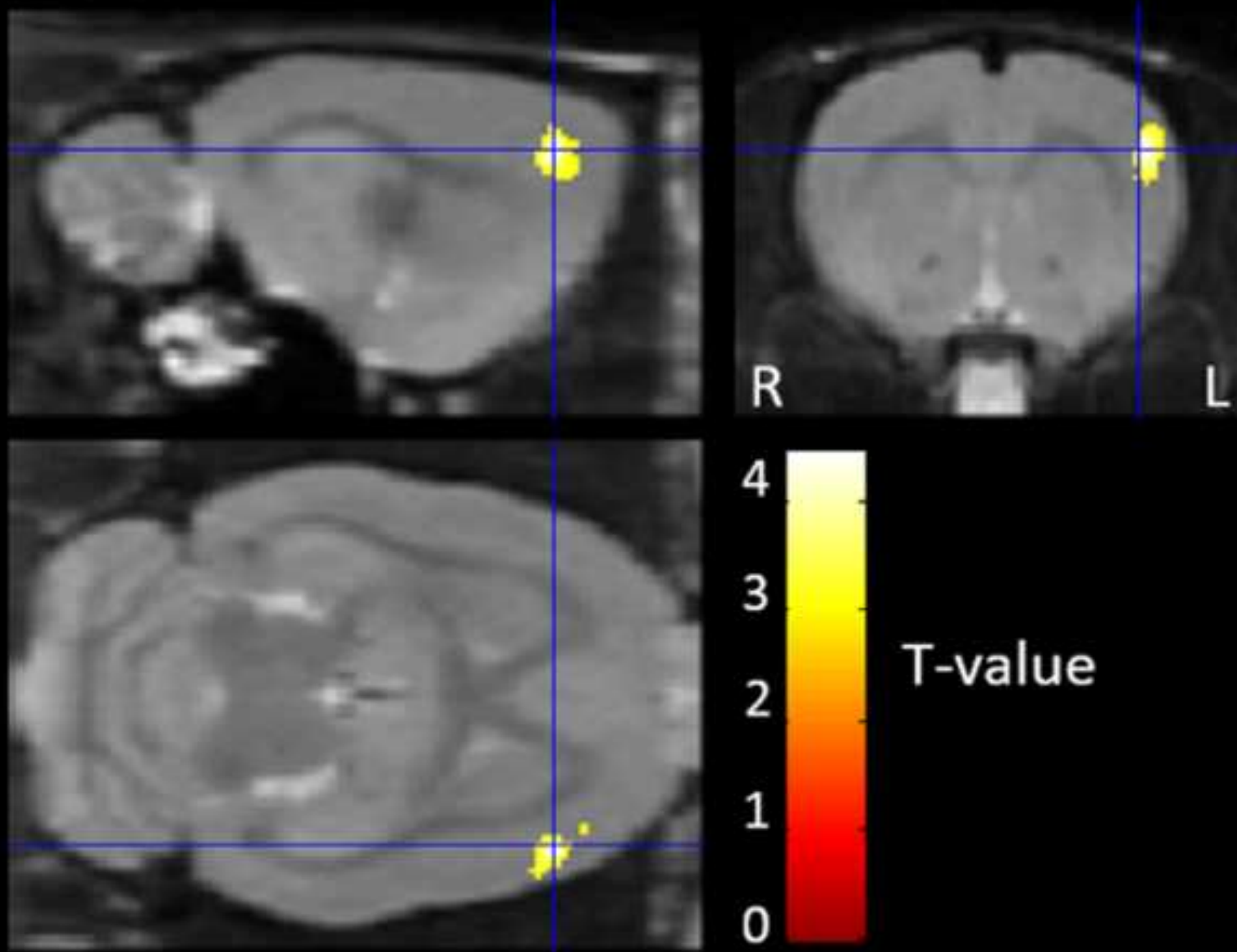
4
3
2
1
0

T-value

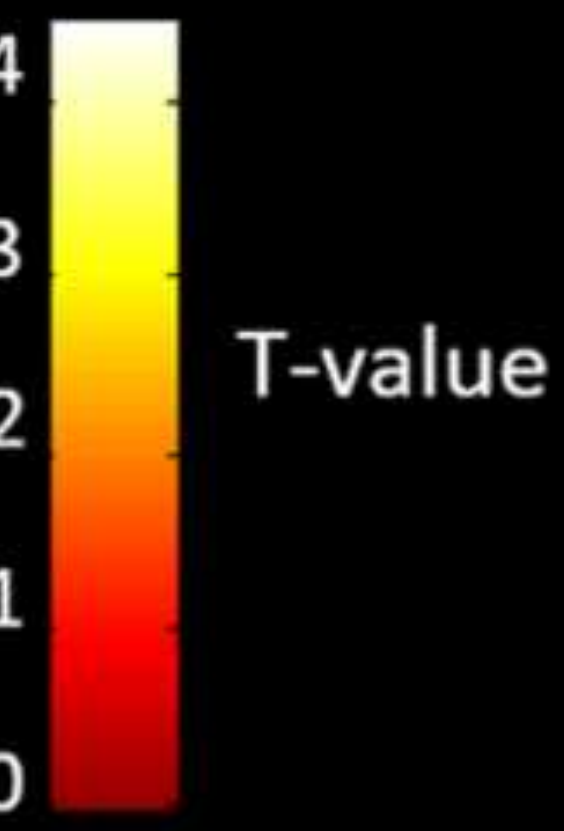



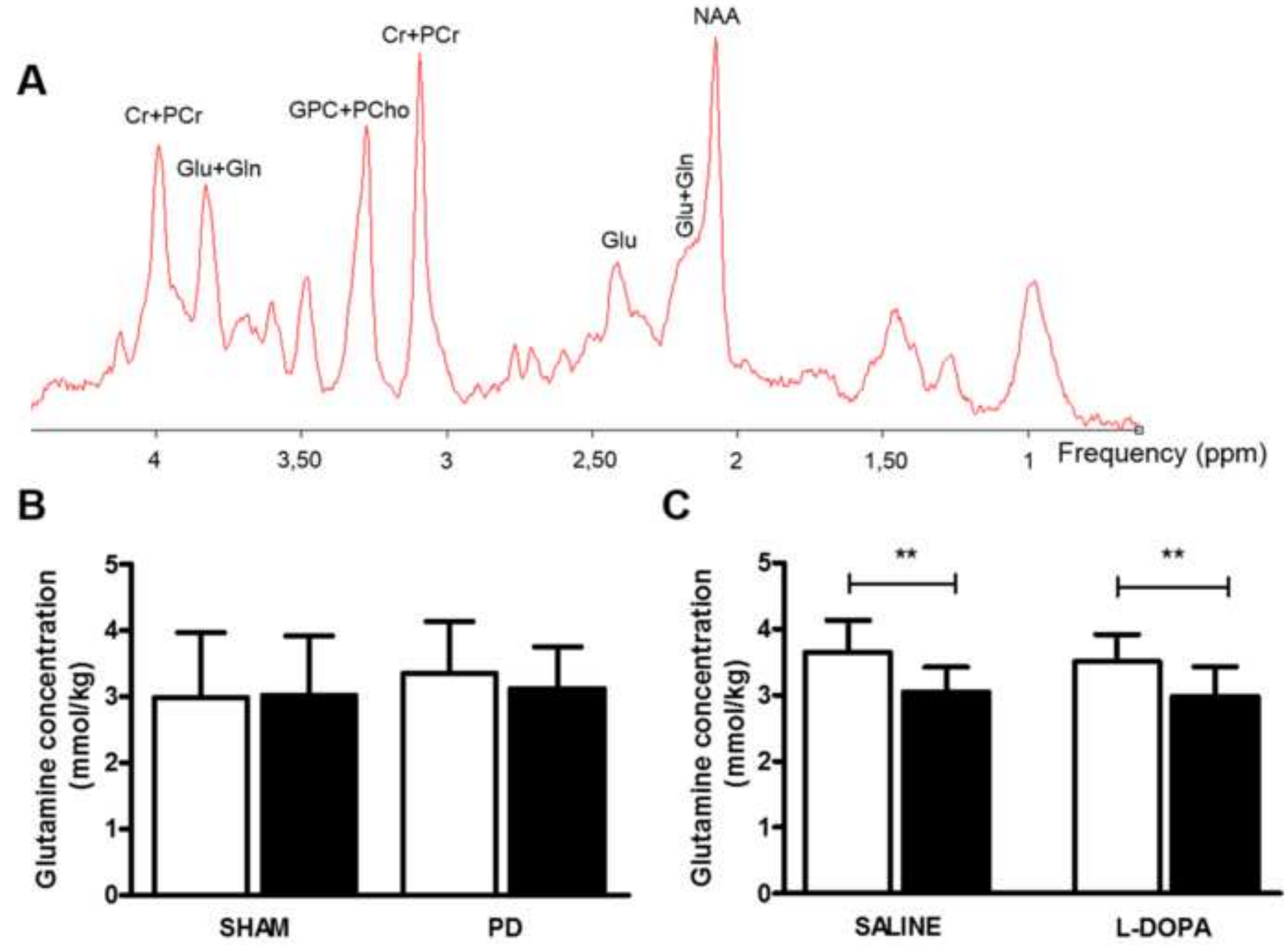

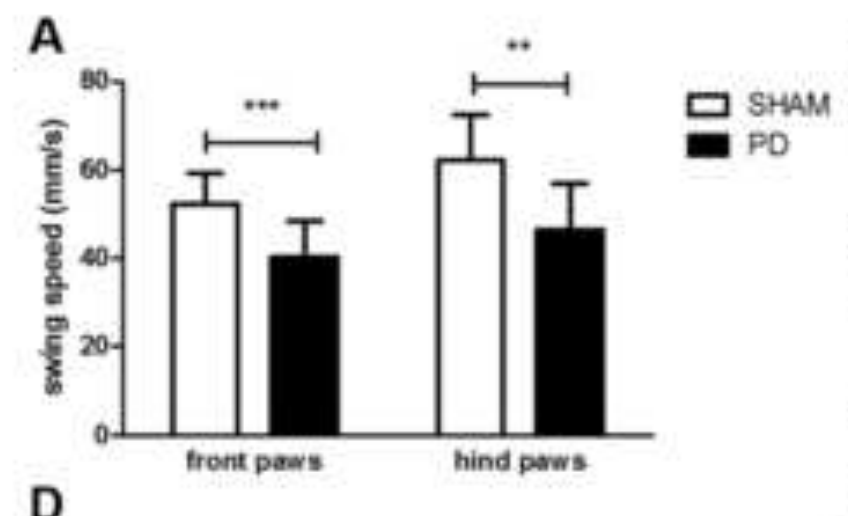

B
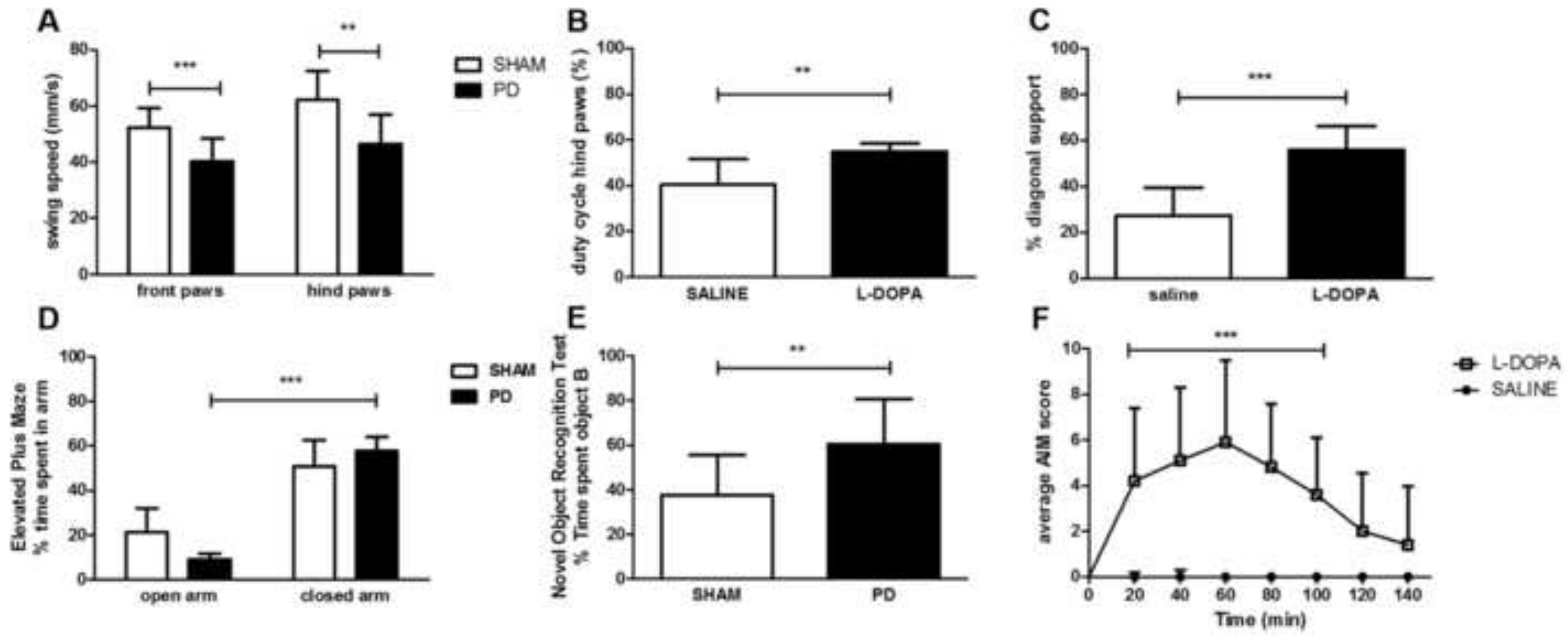


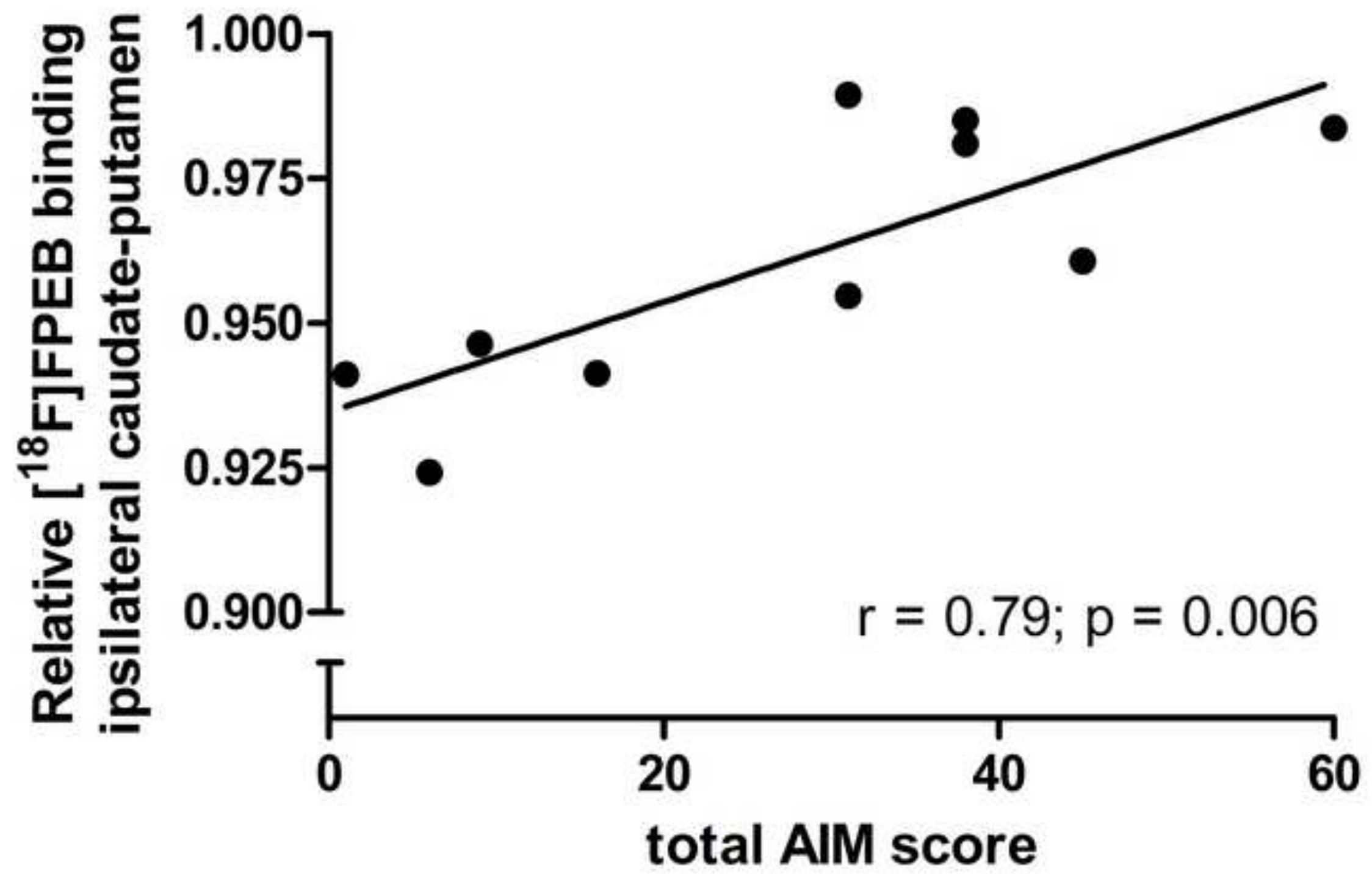




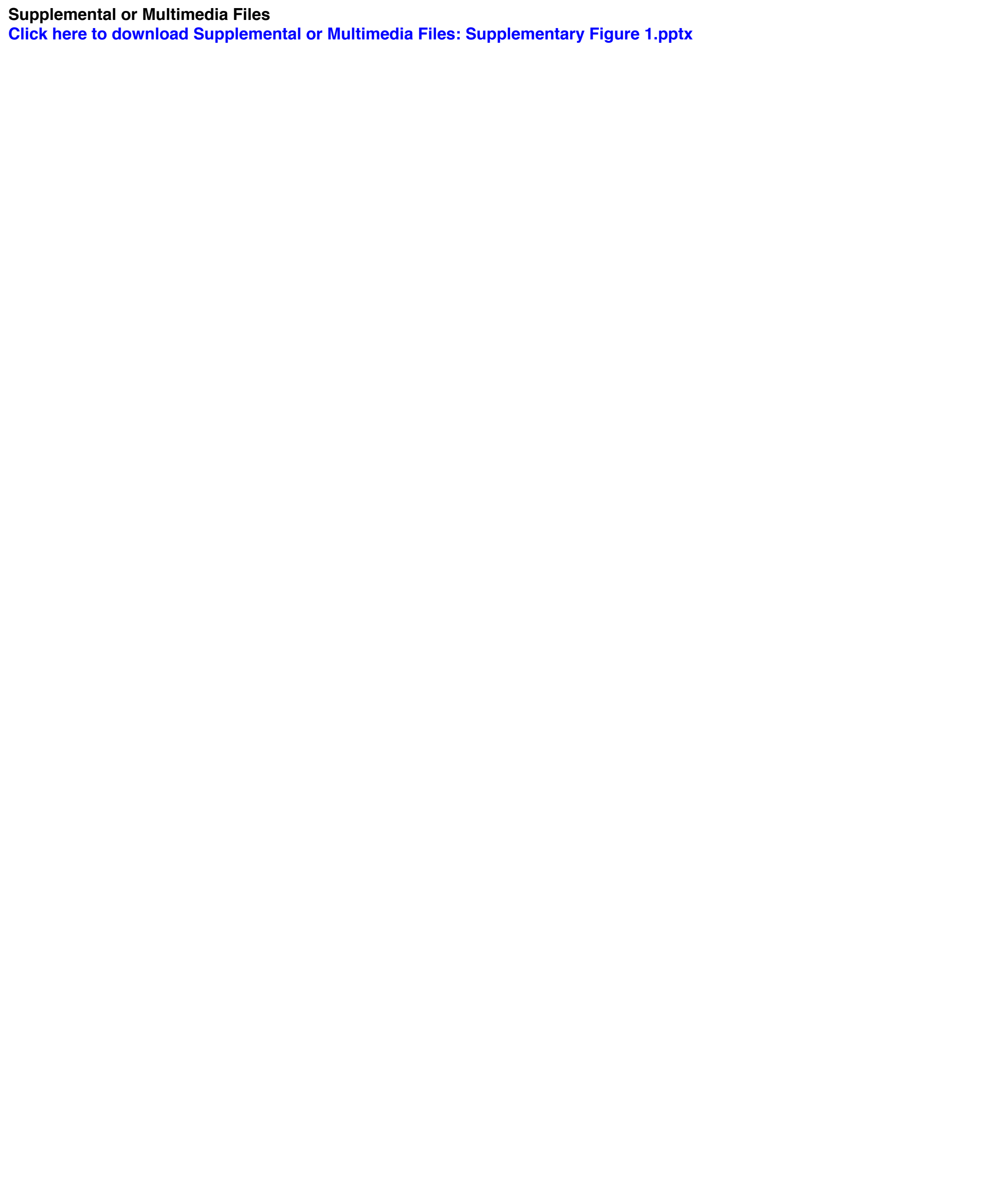

.

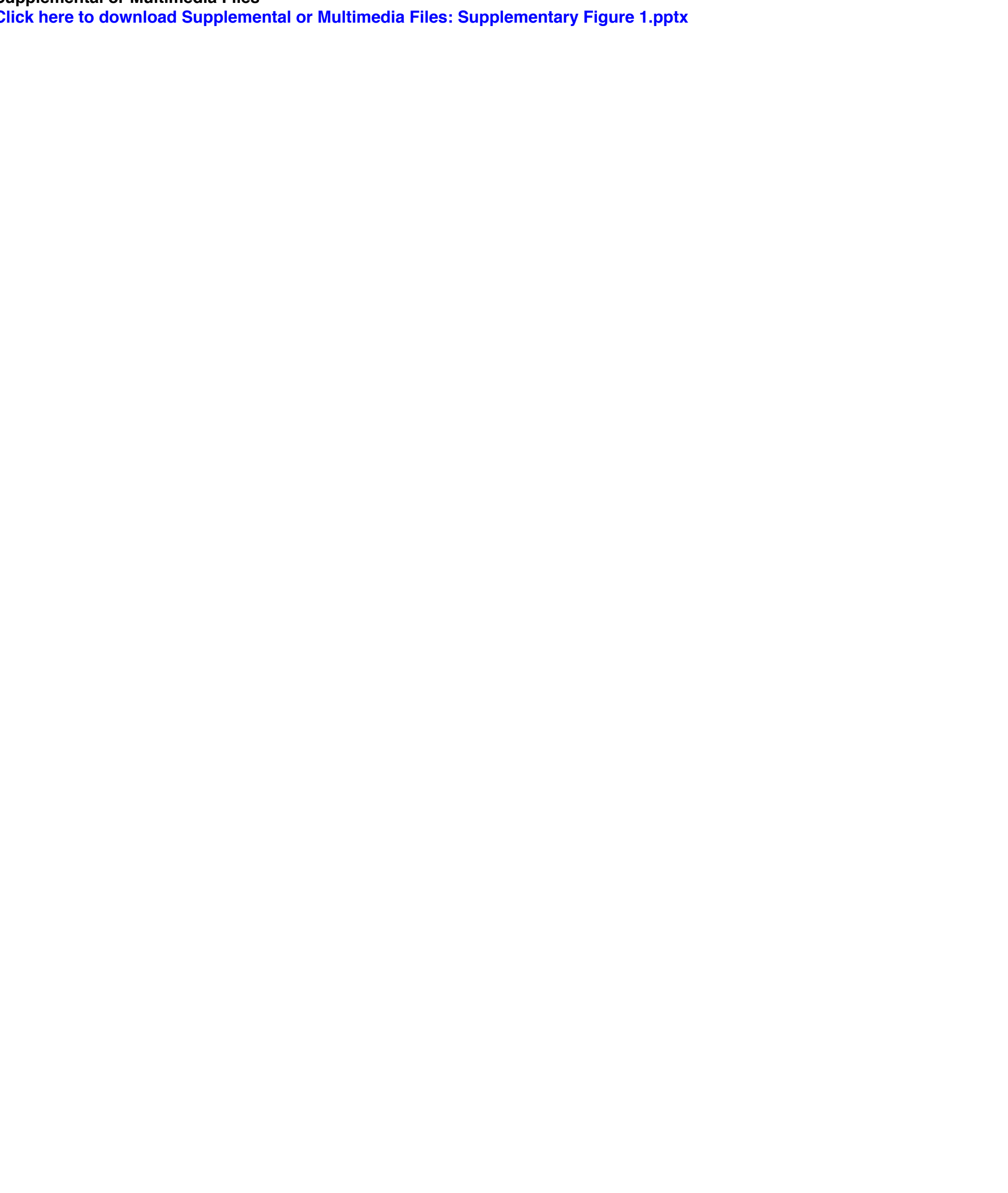
lick here to download Supplemental or Multimedia Files: Supplementary Figure 1.pptx

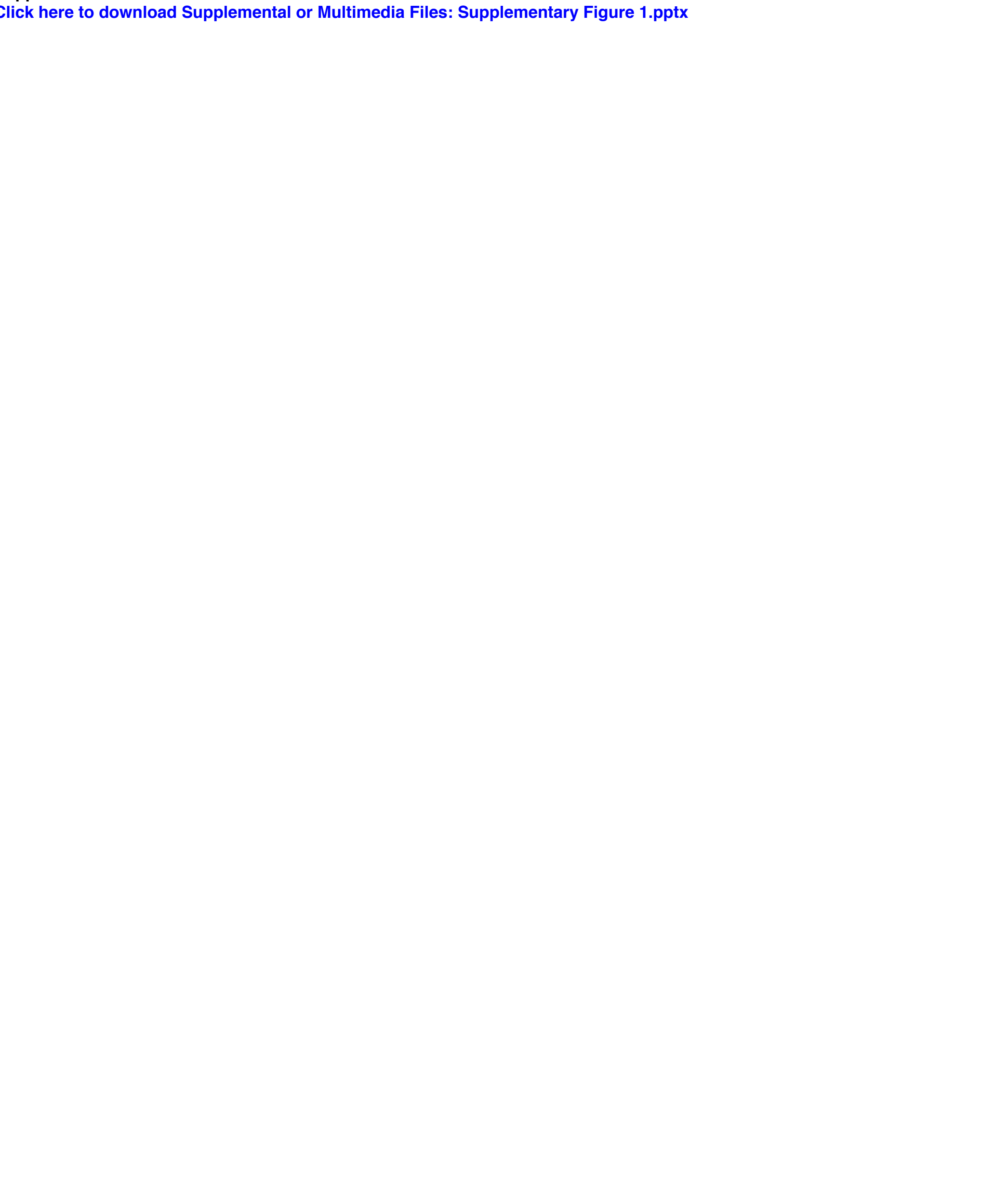
lick here to download Supplemental or Multimedia Files: Supplementary Figure 1.pptx lick here to download Supplemental or Multimedia Files: Supplementary Figure 1.pptx

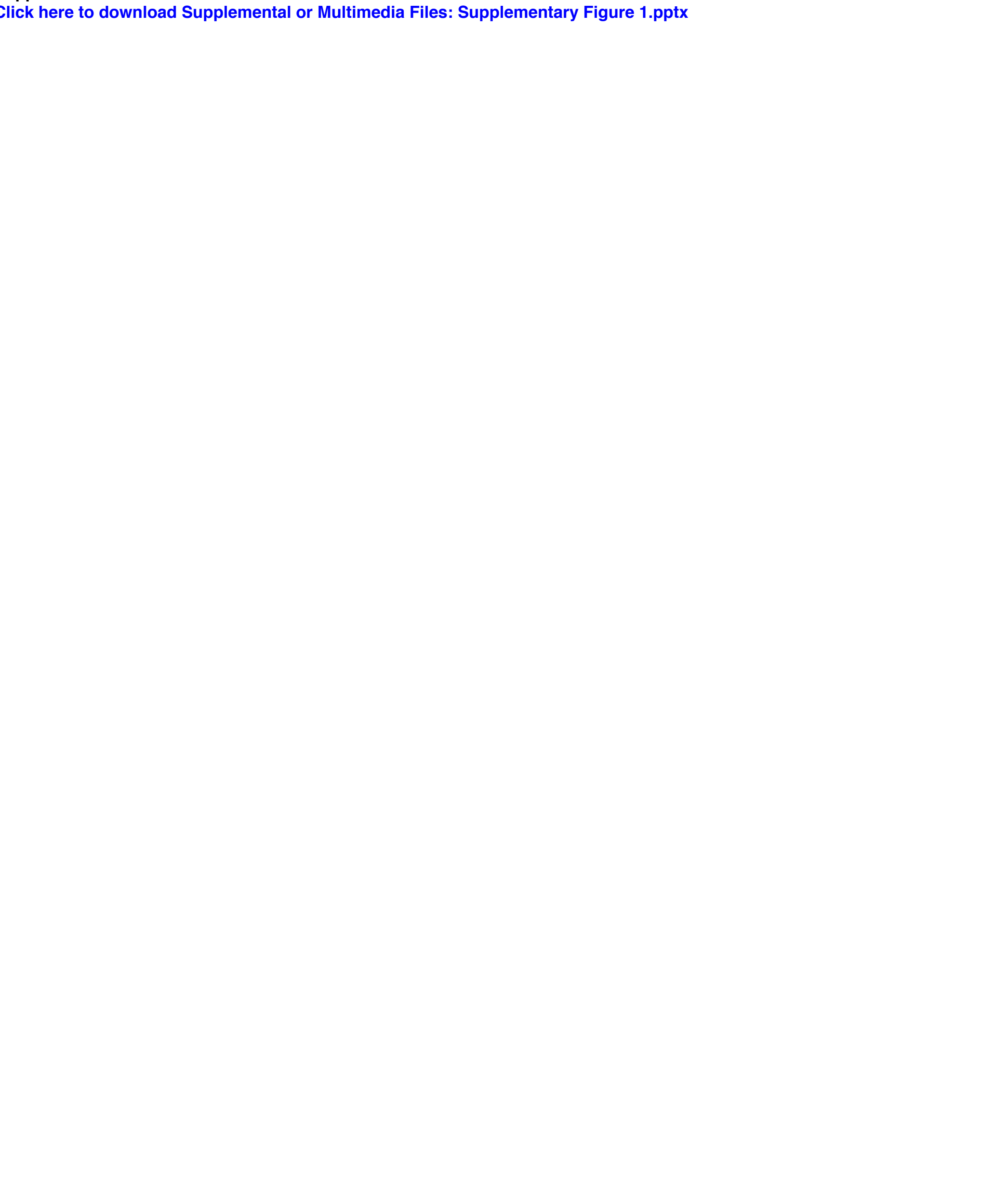
Click here to download Supplemental or Multimedia Files: Supplementary Figure 1.pptx Click here to download Supplemental or Multimedia Files: Supplementary Figure 1.pptx

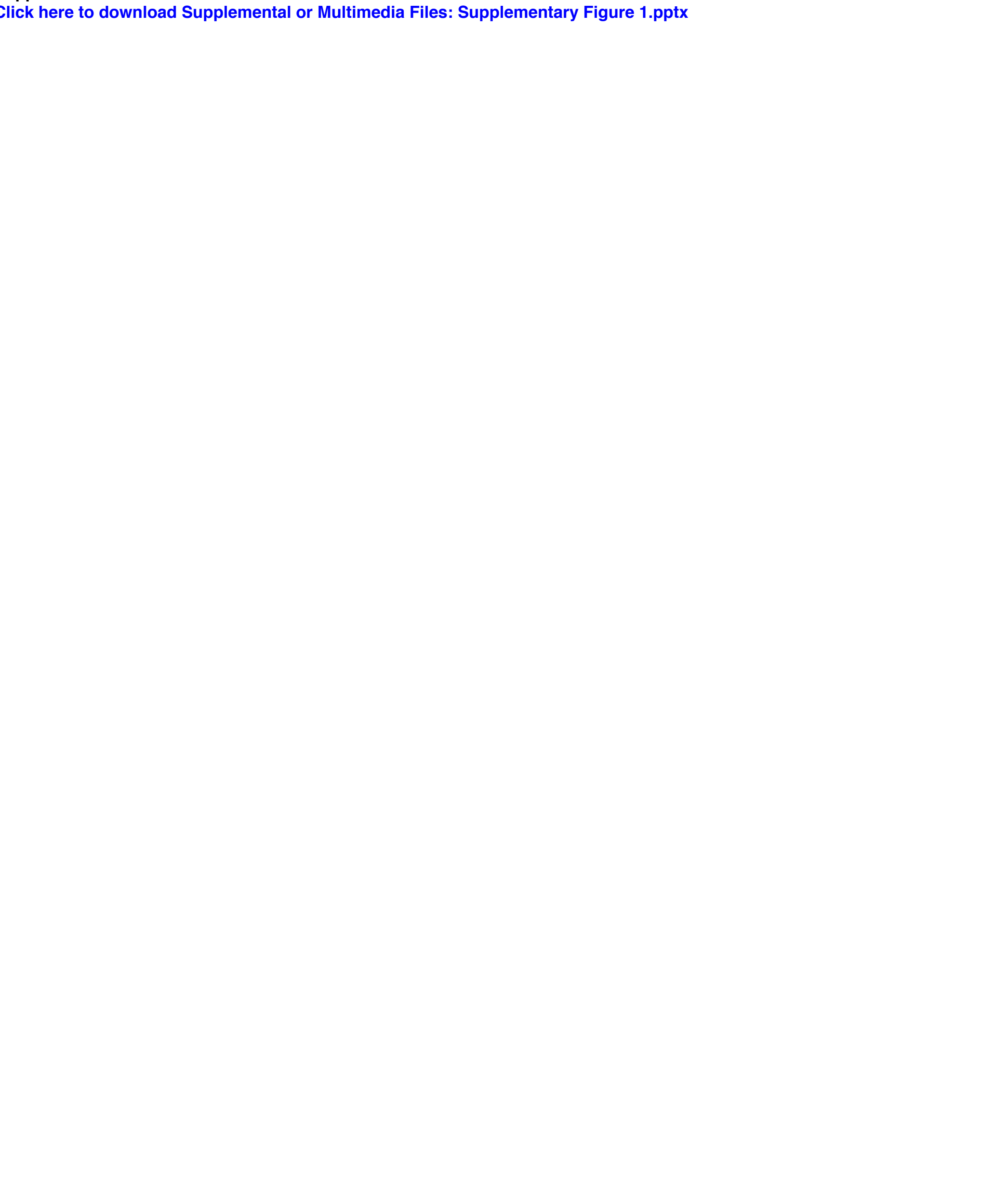

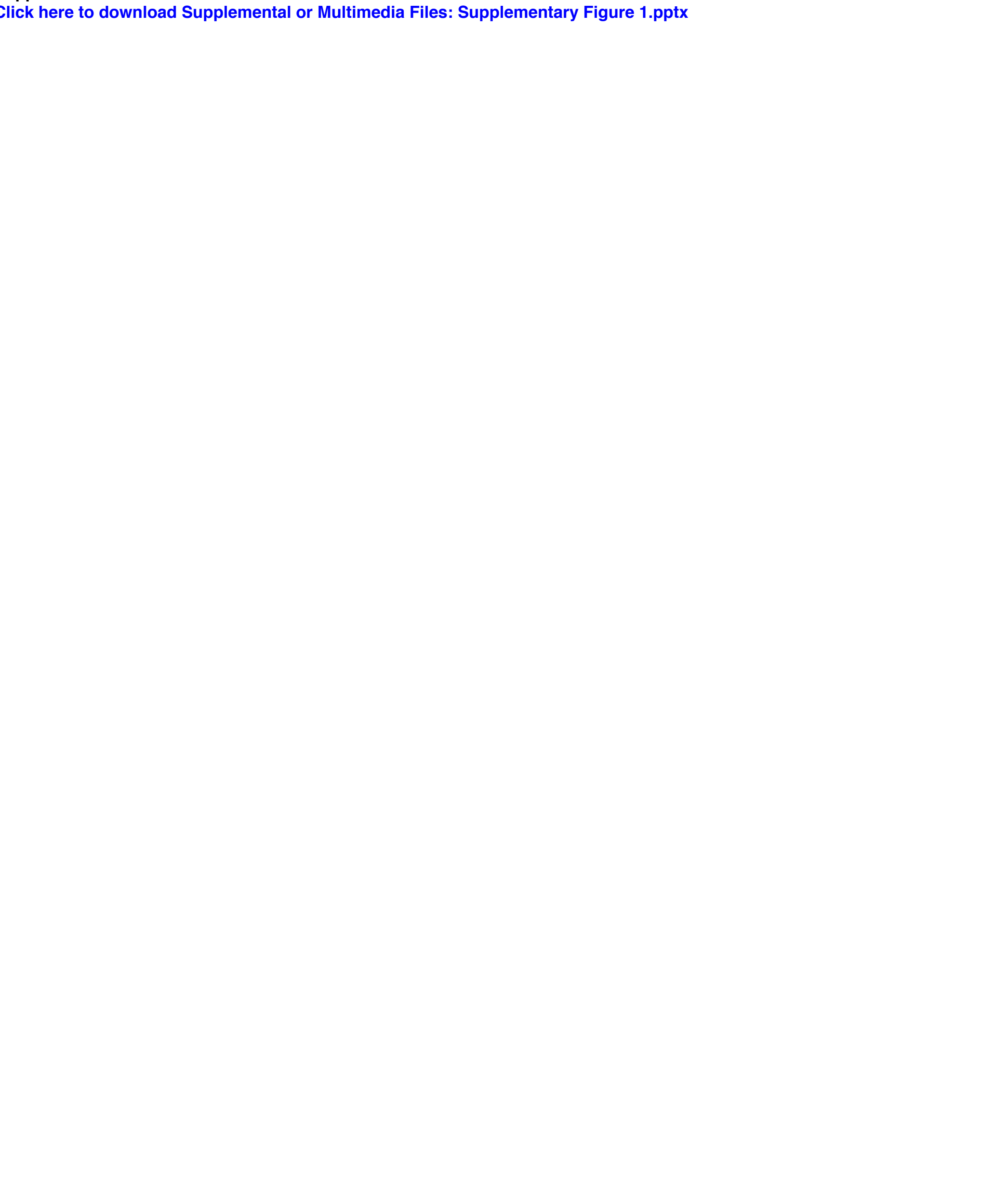
Click here to download Supplemental or Multimedia Files: Supplementary Figure 1.pptx

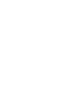
-lick here to download Supplemental or Multimedia Files: Supplementary Figure 1.pptx -lick here to download Supplemental or Multimedia Files: Supplementary Figure 1.pptx -lick here to download Supplemental or Multimedia Files: Supplementary Figure 1.pptx -lick here to download Supplemental or Multimedia Files: Supplementary Figure 1.pptx -lick here to download Supplemental or Multimedia Files: Supplementary Figure 1.pptx -lick here to download Supplemental or Multimedia Files: Supplementary Figure 1.pptx -lick here to download Supplemental or Multimedia Files: Supplementary Figure 1.pptx -lick here to download Supplemental or Multimedia Files: Supplementary Figure 1.pptx -lick here to download Supplemental or Multimedia Files: Supplementary Figure 1.pptx -lick here to download Supplemental or Multimedia Files: Supplementary Figure 1.pptx -lick here to download Supplemental or Multimedia Files: Supplementary Figure 1.pptx -lick here to download Supplemental or Multimedia Files: Supplementary Figure 1.pptx -lick here to download Supplemental or Multimedia Files: Supplementary Figure 1.pptx -lick here to download Supplemental or Multimedia Files: Supplementary Figure 1.pptx -lick here to download Supplemental or Multimedia Files: Supplementary Figure 1.pptx -lick here to download Supplemental or Multimedia Files: Supplementary Figure 1.pptx -lick here to download Supplemental or Multimedia Files: Supplementary Figure 1.pptx -lick here to download Supplemental or Multimedia Files: Supplementary Figure 1.pptx -lick here to download Supplemental or Multimedia Files: Supplementary Figure 1.pptx -lick here to download Supplemental or Multimedia Files: Supplementary Figure 1.pptx -lick here to download Supplemental or Multimedia Files: Supplementary Figure 1.pptx -lick here to download Supplemental or Multimedia Files: Supplementary Figure 1.pptx -lick here to download Supplemental or Multimedia Files: Supplementary Figure 1.pptx -lick here to download Supplemental or Multimedia Files: Supplementary Figure 1.pptx -lick here to download Supplemental or Multimedia Files: Supplementary Figure 1.pptx -lick here to download Supplemental or Multimedia Files: Supplementary Figure 1.pptx -lick here to download Supplemental or Multimedia Files: Supplementary Figure 1.pptx

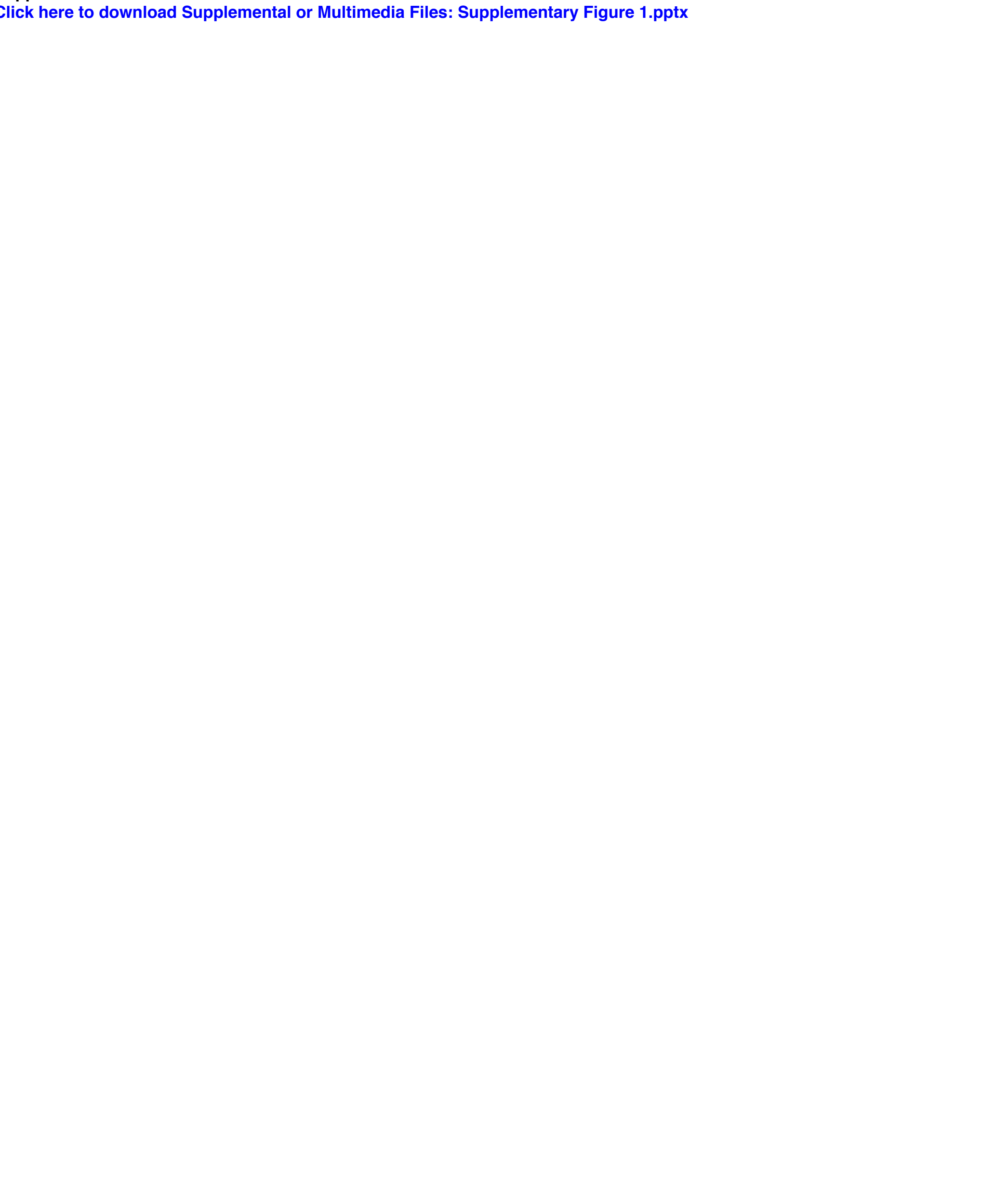




\section{Research highlights}

- We quantified mGluR5 and glutamate/glutamine in 6-OHDA rats with and without LID.

- mGluR5 binding was decreased in the CP and cortical regions of 6-OHDA rats.

- LID rats had higher relative mGluR5 uptake in the motor and somatosensory cortex.

- We found relative mGluR5 uptake to be positively correlated to LID severity.

- Glutamine levels were increased in the contralateral CP of both treatment groups. 